\title{
Role of Oxidative Stress as a Novel Therapeutic Target in Myocardial Injury Due to Ischemia/Reperfusion in Patients with Acute Myocardial Infarction
}

\author{
Pablo Morales-Carreno ${ }^{1}$ \\ Ramon Rodrigo ${ }^{2 \rtimes}$
}

1.: Institute of Biomedical Sciences, Faculty of Medicine, University of Chile, Santiago, Chile. Email:pmoralesc1995@gmail.com

Email:rrodrigo@med.uchile.cl

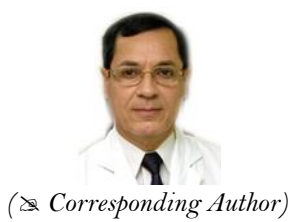

\section{Abstract}

The most effective therapeutic intervention for reducing infarct size and improving outcomes in patients with acute myocardial infarction is the thrombolytic therapy or percutaneous coronary angioplasty. However, this process itself can generate ischemia-reperfusion injury that can be responsible for up to $50 \%$ of the final infarct size. Considering oxidative stress as the main damaging agent in this pathology, it has been postulated that reinforcing antioxidant defenses could improve cardiac function. However, up to date clinical trials based on monotherapies have been consistent in the favorable results. In this review the pathophysiological mechanisms of myocardial injury due to ischemia/reperfusion in patients undergoing percutaneous coronary angioplasty are updated. In addition, new therapeutic alternatives for cardioprotection in this population, are explored, with emphasis in the combined therapy as a novel antioxidant treatment for this myocardial injury.

Keywords: Oxidative stress, Antioxidants, Cardioprotection, Acute myocardial infarction, Vitamin C, Vitamin E, N-acetylcysteine, Polyphenols, Ischemia-reperfusion injury.

Citation | Pablo Morales-Carreno; Ramon Rodrigo (2022). Role of Oxidative Stress as a Novel Therapeutic Target in Myocardial Injury Due to Ischemia/Reperfusion in Patients with Acute Myocardial Infarction. Journal of Life Sciences Research, 9(1): 1-13. Mistory:

History:
Received: 6 December 202

Revised: 12 January 2022

Accepted: 27 January 2022

Published: 9 February 2092

Licensed: This work is licensed under a Creative Commons

Attribution 3.0 License $(\mathrm{cc})$ B $\mathrm{EY}$

Publisher: Asian Online Journal Publishing Group
Funding: This work was supported by the Agencia Nacional de Investigación y Desarrollo (ANID) to a project of the Fondo Nacional de Desarrollo Científico y Tecnológico (Grant number: 1211850).

Authors' Contributions: Both authors contributed to the conception and Authors' Contributio
design of the study.

Competing Interests: The authors declare that they have no conflict of interests.

Transparency: The authors confirm that the manuscript is an honest, accurate, and transparent account of the study; that no vital features of the study have been omitted; and that any discrepancies from the study as planned have been explained.

Ethical: This study followed all ethical practices during writing.

\section{Contents}

1. Introduction

2. Pathophysiology of Myocardial Reperfusion Injury 


\section{Contribution of this paper to the literature}

This review contributes as an updated of the main pathophysiological mechanisms of myocardial injury due to ischemia/reperfusion in patients with acute myocardial infarction, with emphasis in the role of oxidative stress as a therapeutic target that could reinforce the antioxidant defense for cardioprotection.

\section{Introduction}

Cardiovascular diseases (CVDs) are a group of disorders of the heart and blood vessels. It was reported that 17.9 million people died from CVDs in 2019 , representing $32 \%$ of all global deaths [1], among which coronary heart disease (CHD) is the leading cause of death, being responsible for $16 \%$ of total deaths worldwide [2]. This represents an estimated total cost of 196,000 million euros per year in CVDs in Europe, approximately $54 \%$ of the total investment in health [3]. Moreover, CHD was one of the 10 most expensive conditions treated in US hospitals in 2013 (\$9.0 billion) [4].

In ischemic heart disease, cardiomyocyte death almost always occurs in the context of severe and prolonged myocardial ischemic events, which are a consequence of thrombotic complications from atherosclerotic plaques [5]. In most cases, disruption of a vulnerable atherosclerotic plaque or erosion of the coronary artery endothelium generates arterial lumen occlusion and produces a series of biochemical and metabolic changes that eventually lead to the death of cardiomyocytes. This cell death is further exacerbated when the occlusion of the coronary arteries is complete, generating an acute myocardial infarction (AMI) [6].

The most effective therapeutic intervention for reducing the size of a myocardial infarct and improving the clinical outcome is timely and effective restoring of coronary blood flow using either thrombolytic therapy or percutaneous coronary angioplasty, but this process itself can induce further cardiomyocyte death and increased infarct size, a phenomenon known as ischemia-reperfusion injury (IRI), thus reducing the beneficial effects [7, 8]. In fact, IRI can be responsible for up to $50 \%$ of the final infarct size [7].

Although the molecular mechanisms underlying myocardial IRI are not well defined [9], several experimental studies have shown the important role of oxidative stress in this complication, and it has been postulated as a therapeutic target for cardioprotection [10-16]. Therefore, reinforcement of the antioxidant defense system should be expected to protect the myocardium against IRI, however, up to date the results of this proposal has not been successful and needs more studies.

Although multiple therapies appeared to be effective in attenuating reperfusion injury in the experimental setting, translation into clinical practice has not been demonstrated to be consistent [17]. Therefore, the present work describes the pathophysiological mechanisms of myocardial IRI, with emphasis on the role of oxidative stress as a target for novel therapeutic strategies for cardioprotection.

\section{Pathophysiology of Myocardial Reperfusion Injury}

2.1. Alterations in Myocardial Function

The impairment of cardiac function during myocardial reperfusion can generate four types of cardiac dysfunctions [7]:

a) Myocardial stunning, it is defined as mechanical dysfunction that persists after reperfusion, despite the absence of irreversible damage and the restoration of normal or almost normal coronary flow [18]. It is a result from the detrimental effects of oxidative stress [19-21] and intracellular calcium overload on the myocardial contractile apparatus $[19,20,22,23]$. This phenomenon occurs in a wide variety of pathophysiological conditions [20] and the affected zone usually recovers after several days or weeks [7].

b) Reperfusion arrhythmias, is a disturbance of cardiac rhythm that arises as a consequence of a total or partial restoration of flow in tissue which has been previously globally or regionally ischemic [24]. Arrhythmias during or immediately after reperfusion are seen in experimental animal models and in humans [25]. In fact, they are often present in reperfused acute ST-segment elevation myocardial infarction (STEMI) patients, particularly after thrombolysis. In this population, the most commonly encountered reperfusion arrhythmias are idioventricular rhythm, ventricular tachycardia, and fibrillation [26], which usually selfterminate or are easily treated [7, 26, 27]. Early reperfusion arrhythmias are considered evidence of successful reperfusion and vitality of the cardiomyocytes [26].

c) Microvascular "No-reflow", is a phenomenon that describes when the previously occluded epicardial artery restores the blood flow, but it remains the inability to reperfuse the infarct zone [28, 29]. The microvascular obstruction (MVO) is considered the main responsible mechanism, and it causes an irreversible form of damage that results in both myocyte and endothelial cells death [30]. The underlying etiology of MVO is unclear [25], but some factors have been associated, including capillary damage with diminished vasodilation, capillary compression by inflammation of endothelium and cardiomyocyte, micro embolization of particles released from the atherosclerotic plaque, release of vasomotor and thrombogenic substances, and platelet micro-thrombi [31-34].

d) Lethal reperfusion injury (LRI), occurs when, as a consequence of the reperfusion of the infarct area, the damage to the previously affected tissue is enhanced [35]. The role of lethal reperfusion injury as a mediator of cardiomyocyte death is currently controversial. In this regard, they have suggested that reperfusion exacerbates the cellular injury suffered during the ischemic period [36].

\subsection{Cellular Metabolic Alterations}

Adult cardiomyocytes are terminal cells without replicative capacity [37] and with high demand for adenosine triphosphate (ATP). This ATP is provided by the high amounts of mitochondria that cardiomyocytes possess. The aerobic/anaerobic glycolysis and $\beta$-oxidation of free fatty acids generates Acetyl-CoA, which is metabolized through the tricarboxylic acid cycle to supply ATP. Therefore, this cell type works primarily with aerobic metabolism [38].

The metabolic and cellular changes associated with ischemia and subsequent reperfusion are described below: 


\subsubsection{Ischemia}

When the myocardium is exposed to ischemia and AMI, the reduced oxygen supply to the mitochondrial electron transport chain (mETC) causes a drop in the production of ATP. Thus, the glycolytic pathway activates the anaerobic respiration with accumulation of lactic acid $[9,13,39]$. The decrease in intracellular $\mathrm{pH}$ forces the cardiomyocyte to excrete $\mathrm{H}^{+}$through the $\mathrm{Na}^{+} / \mathrm{H}^{+}$exchanger, with the subsequent increase in intracellular $\mathrm{Na}^{+}$. Meanwhile, intracellular ATP depletion deactivates ATPases such $\mathrm{Na}^{+} / \mathrm{K}^{+}$ATPase, which leads to intracellular $\mathrm{Na}^{+}$accumulation [40-42]. Consequently, $\mathrm{Na}^{+}$accumulates within the cell, activating $\mathrm{Na}^{+} / \mathrm{Ca}^{2+}$ exchangers in the reverse direction and increasing cytosolic $\mathrm{Ca}^{2+}[41,43,44]$. Due to ATP depletion, the sarcoplasmic reticulum is unable to uptake $\mathrm{Ca}^{2+}$ from the cytosol because sarcoendoplasmic reticulum $\mathrm{Ca}^{2+}$-ATPase (SERCA) transporter needs ATP to function, resulting in $\mathrm{Ca}^{2+}$ overload [38, 45]. Furthermore, rapid increases in intracellular $\mathrm{Ca}^{2+}$ leads to a non-physiologic opening of the mitochondrial permeability transition pore (MPT) However, the low intracellular $\mathrm{pH}$ is inhibitory [46]. Additionally, activation of intracellular proteases, such as calpain, causes a fragile cellular structure or hypercontracture, leading to contraction band necrosis [38, 44]. Without appropriate restoration of blood supply after ischemia, the lack of ATP content and high $\mathrm{Ca}^{2+}$ levels activate myocyte atrophy, and finally apoptosis and necrosis [47].

\subsubsection{Reperfusion}

Although reperfusion is essential to restore oxygen and nutrients to support cell metabolism and remove byproducts of cellular metabolism, paradoxically, it can by itself inflict further damage. The mechanisms involved in reperfusion injury are complex and multifactorial. This review includes the effects of generation of reactive oxygen species (ROS), cytosolic calcium accumulation, opening of the MPT, and pronounced inflammatory responses Figure 1 [7-9].
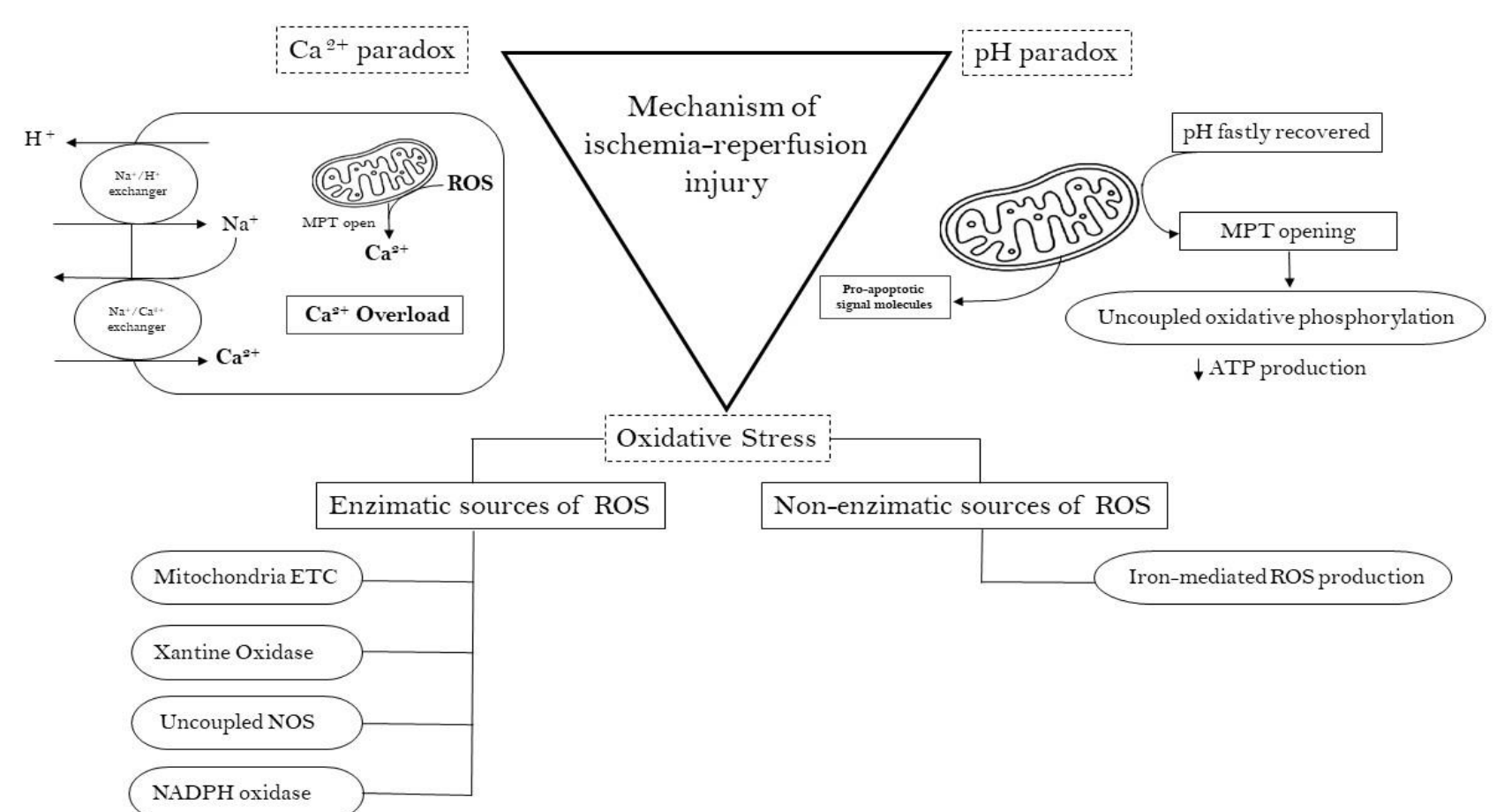

Figure 1. Pathophysiology of Myocardial Ischemia-Reperfusion. The mechanism of ischemia-reperfusion injury includes: (1) Ca ${ }^{2+}$ paradox due $\mathrm{Ca}^{2+}$ overload with MTP opening and activation of $\mathrm{Na}^{+} / \mathrm{H}^{+}$and $\mathrm{Na}^{+} / \mathrm{Ca}^{2+}$ exchangers; (2) the rapidly recovered $\mathrm{pH}$ from acidosis opens the MPT, uncoupling oxidative phosphorylation and ATP production; (3) oxidative stress due to enzymatic and non-enzymatic ROS production.

Note: ROS: reactive oxygen species; MPT: mitochondrial permeability transition pore; ATP: adenosine triphosphate; Mitochondria ETC: mitochondrial Note: ROS: reactive oxygen species; MPT: mitochondrial permed
electron transport chain; Uncoupled NOS: Nitric oxide synthase.

\subsection{Oxidative Stress}

In the first few minutes following the onset of myocardial reperfusion, a ROS burst is produced by different sources $[11,48]$. To control this increases in oxidative stress, the myocardial cells have endogenous free radical scavenging enzymes such as superoxide dismutase (SOD), catalase (CAT) and glutathione peroxidase (GSH-Px) and thioredoxin peroxidase, among others [49]. In addition, nitric oxide (NO) derived from endothelial nitric oxide synthase (eNOS) and neuronal nitric oxide synthase (nNOS) are thought to protect against myocardial IRI by their cardioprotective effect [50]. Further, there are non-enzymatic antioxidant defenses, such as ascorbic acid, $\alpha$-tocopherol, reduced glutathione (GSH), coenzyme Q10, cysteine, carotenoids, flavonoids, polyphenols, and other various exogenous antioxidants that are currently taken in the diet or as supplements. There are many mechanisms whereby antioxidants may act such as (1) scavenging ROS or their precursors, (2) inhibiting the formation of ROS, (3) attenuating the catalysis of ROS generation via binding to metal ions, (4) enhancing endogenous antioxidant generation, and (5) reducing apoptotic cell death by up-regulating the antiapoptotic gene Bcl-2 [35, 51].

The ROS production sources can be enzymatic or non-enzymatic, and their role in the pathophysiology of IRI will be addressed.

\subsubsection{Enzymatic Sources of ROS Production \\ 2.3.1.1. Mitochondria}

There are different sites in the mETC in mammalian mitochondria generating superoxide anion $\left(\mathrm{O}_{2}{ }^{-}\right)$and/or hydrogen peroxide $\left(\mathrm{H}_{2} \mathrm{O}_{2}\right)$. Electrons derived from $\mathrm{NADH}$ or some other donor can directly react with oxygen and 
generate $\mathrm{O}_{2}-$, primarily at complexes I and III, causing partial reduction of molecular oxygen to $\mathrm{O}_{2}-$ instead of reduction to $\mathrm{H}_{2} \mathrm{O}[52,53]$ Particularly, reverse electron transport at complex $\mathrm{I}$ is the main source of $\mathrm{O}_{2}-\mathrm{upon}$ reperfusion of ischemic tissue [54,55].

\subsubsection{Xanthine Oxidoreductase}

It can be found in two interconvertible forms: xanthine dehydrogenase $(\mathrm{XDH})$ preferably using $\mathrm{NAD}^{+}$as the electron acceptor; and xanthine oxidase $(\mathrm{XO})$ using $\mathrm{O} 2$ as the terminal electron acceptor. Xanthine oxidoreductase catalyzes the transformation of hypoxanthine and xanthine to uric acid, with $\mathrm{O}_{2}-$ or $\mathrm{H}_{2} \mathrm{O}_{2}$ generation as byproducts. Moreover, under acidic conditions ( $\mathrm{pH} \sim 6.5$ ), XDH may oxidize NADH instead of xanthine, thus promoting $\mathrm{O}_{2}$ - production [56-58].

\subsubsection{Uncoupled Nitric Oxide Synthase}

While NO derived from constitutive eNOS and nNOS protect against IRI, the inducible nitric oxide synthase (iNOS) derived ones aggravate the damage, causing cardiac hypertrophy and oxidative stress [50]. Tetrahydrobiopterin $\left(\mathrm{BH}_{4}\right)$ is an essential NOS co-factor, however $\mathrm{BH}_{4}$ is oxidized in the presence of ROS. Consequently, in the absence of L-arginine, $\mathrm{BH}_{4}$, or both, eNOS changes to its uncoupled condition and become a source of $\mathrm{O}_{2}$ - rather than $\mathrm{NO}$, and contribute to oxidative stress [59-61]. Additionally, it has been demonstrated that the iNOS is increased after the reperfusion, producing large amounts of NO and leading to direct cytotoxic effects, or reacting with $\mathrm{O}_{2}$ - to form the highly oxidizing agent peroxynitrite $\left(\mathrm{ONOO}^{-}\right)$that causes further cell damage [62-65].

\subsubsection{Reduced Nicotinamide Adenine Dinucleotide Phosphate (NADPH) Oxidase}

NADPH oxidase isoforms (NOXs) are members of a transmembrane proteins family that transport electrons donated by NADPH across biological membranes, leading to reduce $\mathrm{O}_{2}$ to $\mathrm{O}_{2}$-. Some studies have shown that NOX can also produce $\mathrm{H}_{2} \mathrm{O}_{2}$ [66-68]. Seven isoforms have been described previously: NOX1 to NOX5, dual oxidase- (DUOX-) 1 and DUOX-2 [66, 67, 69, 70]. DUOX-1, DOUX-2 and NOX4 predominantly produce $\mathrm{H}_{2} \mathrm{O}_{2}$. On the other hand, the remaining NOX isoforms produce mostly $\mathrm{O}_{2}-[53,66,71]$. NOX $1, \mathrm{NOX}_{2}$, NOX4 and NOX 5 are highly expressed in cardiovascular system; and specifically up-regulation of NOX2 and NOX4 are related to oxidative stress via production of $\mathrm{O}_{2}-$ and $\mathrm{H}_{2} \mathrm{O}_{2}$ in hearts subjected to IRI $[53,72,73]$.

\subsubsection{Non-Enzymatic Sources of ROS Production}

The non-enzymatic generation of ROS occurs in the presence of metal ions, such as iron ones [74]. To understand this mechanism, it is necessary to describe iron homeostasis:

This essential element is necessary for cell survival, in fact cardiomyocytes are sensitive to iron deficiency because they require large amounts of mitochondria with its enzymes that contain hemoproteins. However, they also are poorly protected against iron overload [75]. Therefore, the role of ferritin (FT) as the main ion storage in a non-toxic and readily available manner is essential. The small percentage of total intracellular iron (less than 5\%) that does not bind to FT is defined as a labile iron pool (LIP), and exists in the cytosol, in the mitochondrial matrix, and lysosomes as a redox-active iron pool $[76,77]$. If FT becomes saturated, the LIP will be increased and it will be incorporated into the Fenton reaction Equation 1 and Haber-Weiss reaction Equation 2, producing ROS. The Fenton reaction is a chemical reaction between ferrous iron $\left(\mathrm{Fe}^{2+}\right)$ and $\mathrm{H}_{2} \mathrm{O}_{2}$, which produces hydroxyl radical $(\mathrm{OH})$. On the other hand, in the Haber-Weiss reaction, ferric iron $\left(\mathrm{Fe}^{3+}\right)$ is reduced back to $\mathrm{Fe}^{2+}$ in the presence of $\mathrm{O}_{2}$ - radicals $[77,78]$.

$$
\begin{gathered}
\mathrm{Fe}^{2+}+\mathrm{H}_{2} \mathrm{O}_{2} \rightarrow \mathrm{Fe}^{3+}+-\mathrm{OH}+\cdot \mathrm{OH} \quad \text { Fenton Reaction } \\
\mathrm{O}_{2}^{\cdot-}+\mathrm{H}_{2} \mathrm{O}_{2} \rightarrow \mathrm{O}_{2}+-\mathrm{OH}+\cdot \mathrm{OH} \quad \text { Haber-Weiss reaction }
\end{gathered}
$$

During IRI, iron-mediated non-enzymatic ROS production can trigger cell death processes such as apoptosis, necroptosis, pyroptosis, and ferroptosis [77]. Among these, ferroptosis highlights as a regulated form of necrosis caused by the accumulation of lipid peroxidation products and ROS production derived from iron metabolism, mainly when GSH levels in the cell are depleted or when the enzyme GSH-Px4 is inhibited [79]. GSH-Px4 can inhibit ferroptosis by converting phospholipid hydroperoxides to lipid alcohols using GSH [80].

Both GSH-Px4 and acyl-CoA synthetase long-chain family member 4 (ACSL4) are recognized biomarkers of ferroptosis, and it has been reported that when an ischemic rat heart is reperfused there is greater expression of ACSL4 and lower levels of GSH-Px4. And this response is not replicated in the ischemic phase [81]. In addition, a previous study showed that ferroptosis was more active $30 \mathrm{~min}$ after reperfusion and not during other moments of this phase [82].

In summary, the iron overload can induce a non-enzymatic production of ROS via Fenton and Haber-Weiss reactions. The product of oxidative stress can potentially lead to cellular death mediated by ferroptosis, which is produced in myocardial IRI and may be related to the extent of the infarct size [74]. The latest results related to IRI-ferroptosis are important to take into consideration for the development of cardioprotective therapies based on ferroptosis inhibition to reduce heart IRI.

\section{4. $\mathrm{Ca}^{2+}$ Paradox}

During reperfusion, there is a rapid restoration of essential substrates for the generation of ATP, such as glucose or free fatty acids, an instantaneous increase in oxygen supply and a prompt normalization of the extracellular $\mathrm{pH}$. This creates an extreme $\mathrm{H}^{+}$gradient across the plasma membrane that triggers the $\mathrm{Na}^{+} / \mathrm{H}^{+}$ exchanger, leading to a massive $\mathrm{Na}^{+}$influx with $\mathrm{H}^{+}$outflow to the extracellular [38]. This gradient can trigger the inverted action of the surface $\mathrm{Na}^{+} / \mathrm{Ca}^{2+}$ exchanger, which excretes accumulated $\mathrm{Na}^{+}$but leads to intracellular $\mathrm{Ca}^{2+}$ overload [83]. Therefore, excess of $\mathrm{Ca}^{2+}$ induces cardiomyocyte death by causing hypercontracture of the heart cells and MPT opening [7]. 
In parallel, upon re-oxygenation the xanthine oxidase is activated by $\mathrm{Ca}^{2+}$-sensitive proteases, increasing $\mathrm{ROS}$ production [84]. Also, under oxidative stress conditions, $\mathrm{Ca}^{2+}$ is induced by ROS to influx into the cytoplasm and then influx into the mitochondria via mitochondrial $\mathrm{Ca}^{2+}$ uniporter, resulting in the opening of MPT, the collapse of mitochondrial membrane potential, and release of apoptotic signaling molecules such as cytochrome c and apoptosis-inducing factor (AIF) from the intermembrane space [85-88].

After 30-60 min of reperfusion, a gradual recovery of $\mathrm{Ca}^{2+}$ excretion and ATP-dependent $\mathrm{Ca}^{2+}$ reuptake in sarcoplasmic reticulum (SR) takes place, and the cells return to normal homeostasis. This ischemia-reperfusion process makes the intracellular $\mathrm{Ca}^{2+}$ concentration dual peaked [89], with one peak occurring at $15-60$ min after the onset of index ischemia and the other peak occurring within 30 min of reperfusion [38].

Experimental studies have shown that pharmacologic antagonists of the sarcolemmal $\mathrm{Ca}^{2+}$ channel [90] or the mitochondrial $\mathrm{Ca}^{2+}$ uniporter [91], administered at the onset of myocardial reperfusion, reduce MI size by up to $50 \%$. However, clinical studies of calcium channel blockers administered at the onset of myocardial reperfusion have not shown beneficial results [92].

\section{5. pH Paradox and MTP Opening}

Once the reperfusion has started, the previously lowered $\mathrm{pH}$ is rapidly restored by the washout of lactate, the activation of the $\mathrm{Na}^{+} / \mathrm{H}^{+}$exchanger and the $\mathrm{Na}^{+}-\mathrm{HCO}_{3}-$ symporter. This can contribute to lethal reperfusion injury, and is termed the pH paradox [93]. This effect may be mediated by the opening of the MPT, which is a non-selective channel of the inner mitochondrial membrane that is closed under physiological conditions [94]. During ischemia, the susceptibility of the MPT is increased, but the pore remains closed when the pH is low. However, when $\mathrm{pH}$ is rapidly recovered, the neutralization of the acid media triggers the actual MPT opening, thus allowing passage through the inner mitochondrial membrane of molecules $>1.5 \mathrm{kDa}$, leading to uncoupled oxidative phosphorylation and disrupting ATP production [95]. To date, the molecular nature of the MPT is still unclear [96]. Moreover, preventing MPT opening at the time of reperfusion by administering MPT inhibitors (such as the immunosuppressant cyclosporin A) at the onset of myocardial reperfusion has been reported in experimental studies to reduce infarct size by $40 \%-50 \%$ in small and large animal models [97-100]. However, in clinical studies, delaying the restoration of physiologic $\mathrm{pH}$ during myocardial reperfusion using $\mathrm{Na}^{+} / \mathrm{H}^{+}$exchange inhibition did not protect the heart [41, 101].

\subsection{Inflammation}

It is unclear whether the inflammatory response that accompanies an AMI contributes to the pathogenesis of myocardial LRI or whether it is a reaction to the acute myocardial injury [102]. Nevertheless, it has been reported the release of chemoattractant draws neutrophils into the infarct zone during the first 6 hours of myocardial reperfusion, and during the next 24 hours they migrate into the myocardial tissue. These neutrophils cause vascular plugging and release degradative enzymes, along with $\operatorname{ROS}[7,102]$.

The association between high ROS production and inflammation is mediated by the pro-inflammatory transcription factor, nuclear factor kappa-light-chain-enhancer of activated B cells (NF- $\kappa \mathrm{B})$, which is sensitive to

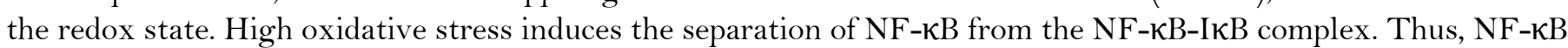
alone translocates into the nucleus, where it interacts with the genome and stimulates the expression of genes for inflammatory cytokines, leading to the initiation of the inflammatory response [103].

Finally, through the ischemia and reperfusion models of multiple organs, Toll-like receptors have been demonstrated to play an important bridging role in the interaction between oxidative stress and inflammatory response [104]. It is thought that ROS up-regulates IL-1 $\beta$ through the NLRP3 inflammasome activation and caspase-1 expression [105]. It was demonstrated that thioredoxin-interacting protein mediated NLRP3 inflammasome activation in cardiac microvascular endothelial cells was a novel mechanism of MI/RI [106].

\section{Therapeutic Focus for Myocardial Reperfusion Injury}

In patients with $\mathrm{AMI}$, the opportunity to intervene is limited between the onset of myocardial ischemia and the time of myocardial reperfusion. However, therapeutic targeting of the individual components of myocardial LRI, including oxidative stress, calcium overload, $\mathrm{pH}$ correction, and, more recently, inflammation have produced disappointing results [107, 108]. Nevertheless, there have been emerging therapeutic strategies for preventing myocardial LRI in the last years.

The concept of "ischemic conditioning" includes several endogenous cardioprotective strategies, applied either directly to the heart (ischemic preconditioning or post-conditioning) or to another region of the body, for example a limb (remote ischemic preconditioning, preconditioning or post-conditioning [109, 110]. In this regard, ischemic preconditioning (IPC) is one of the most potent cardioprotective strategies against IRI, originally described by Murry, et al. [111]. Sub-lethal amounts of ROS can serve as a trigger for IPC by functioning as signaling messengers to protect against LRI. In the early phase of IPC, post-translational modification of redox-sensitive proteins provides cardioprotective signal transduction pathways [53]. On the other hand, the late phase of IPC is mediated by cardioprotective gene expression, like hypoxia-inducible factor 1 (HIF-1), which generates low amounts of mitochondrial ROS that is going to act as intracellular signals [112]. Although the molecular mechanism triggered by HIF that leads to sub-lethal ROS accumulation remains unknown [53], it has been hypothesized that HIF-induced pathways seem to converge on Akt activation and inhibition of MTP opening [113-116].

In parallel to ischemic conditioning, there are many drugs that can reduce myocardial IRI, mainly based on their antioxidant capacity.

\subsection{Ascorbic Acid}

Vitamin C (Vit C), ascorbic acid or ascorbate is a water-soluble antioxidant agent that acts as a ROS scavenger. Oral ingestion of fruits, vegetables or supplements is the primary route of administration for Vit C [117]. Although low plasma concentrations are achieved, between $100 \mu \mathrm{mol} / \mathrm{L}$ or $150 \mu \mathrm{mol} / \mathrm{L}$ with food intake and 
supplementation, intravenous injection of ascorbate has been reported to lead to concentrations reaching 25 to 30 $\mathrm{mmol} / \mathrm{L}$ in plasma [118]. However, its intracellular levels and plasma levels do not always have a correlation in cells other than red blood cells, since ascorbate tends to accumulate within the cell [35].

Due to its properties, Vit $\mathrm{C}$ can be found in two states: the reduced form, ascorbic acid, and the oxidized form, dehydroascorbic acid (DHA) [119]. SVCT1 and SVCT2 are the $\mathrm{Na}^{+}$-dependent Vit C transporters, responsible for entering ascorbic acid into the cell [120], while the glucose transporters GLUT1, GLUT3, and GLUT4 are responsible for the DHA entry [119]. All three types of glucose transporters are expressed in the myocardium [35]. Vit C antioxidant potential is explained by its ability to donate electrons, being oxidized to DHA. Later it returns to its reduced form after being used by the cell [121].

By acting as an electron donor, ascorbic acid generates ascorbyl radical, and it is capable of being oxidized by acting as an antioxidant or enzymatic cofactor [121]. So it is now accepted that Vit $\mathrm{C}$ together with glutathione constitute the primary cellular defenses against ROS production [122]. In this regard, it has been shown an inverse correlation between Vit C plasma concentration and products of oxidative damage to DNA, proteins and lipids in healthy adult nonsmoking population [123]. In another study where oxidative and antioxidant parameters were evaluated in patients with AMI before and after reperfusion, it was found that the activity of the antioxidant enzyme SOD decreased, while the activity of the oxidant enzyme XO increased in conjunction with the marker of lipid peroxidation malondialdehyde (MDA) after thrombolysis. Patients who were supplemented with postreperfusion oral Vit $\mathrm{C}$ showed improvements in these parameters to almost normal levels [124]. Also, in another IRI model, it has been reported that Vit $\mathrm{C}$ administered after the reperfusion decreases lactate dehydrogenase $(\mathrm{LDH})$ levels in blood, as a marker of oxidative stress [125]. In addition, a significant decrease in hydroperoxides concentration at 48 hours post reperfusion [126] and a decrease in 8-isoprostanes after 6-8-hour post reperfusion [127], has been described following the administration of Vit C. The results of several studies [128-130] have shown a significant decrease in the levels of 8-hydroxy-2'-deoxyguanosine, a marker of oxidative damage to DNA, post reperfusion and administration of Vit $\mathrm{C}$. In the same way, the treatment with Vit $\mathrm{C}$ caused a significant decrease in 8-iso-prostaglandin $\mathrm{F} 2$ alpha at 6-8 hours after reperfusion [128], that is, it decreased the peroxidation of arachidonic acid in lipid membranes.

Vitamin $\mathrm{C}$ must reach a plasma concentration of $10 \mathrm{mml} / \mathrm{L}$ to displace the reaction of the $\mathrm{O}_{2}-\mathrm{radical}$ with $\mathrm{NO}$, which acts at a rate 105 times faster than the reaction between ascorbic acid and the superoxide anion radical [35, 131]. But when it has been administered at higher concentrations prior to reperfusion, no significant improvements have been observed in reducing the infarct size [132]. However, there are few studies of Vit C in human IRI models, so the results are not conclusive. Other limitations of the current evidence are the lack of consideration of basic aspects such as the mechanistic approach of the drug and its pharmacokinetic properties [133, 134].

Although the administration of Vit $\mathrm{C}$ improves the total antioxidant capacity at 48 hours after reperfusion, it has been observed that the GSH/GSSG ratio decreased significantly in the groups supplemented with Vit C [127, 132]. Likewise, in a setting of myocardial IRI, Vit $\mathrm{C}$ at high doses could activate the Fenton reaction due the iron overload and acting as a pro-oxidant species [74].

In addition to these results, it has been described multiples antioxidant effects of Vit C:

i. Synergistic effects with vitamin E (Vit E), ascorbic acid recycles $\alpha$-tocopherol $(\alpha$-TOH) into lipid bilayers and erythrocytes [35]. Also, in conjunction with Vit E, Vit C is able to up-regulate eNOS activity [135].

ii. Decrease in ROS production by the down-regulation of NOX enzymes activity [136].

iii. Suppression in NF- $\kappa \mathrm{B}$ activation induced by tumor necrosis factor $\alpha(\mathrm{TNF}-\alpha)[137]$.

iv. It prevents the oxidation of $\mathrm{BH}_{4}$, cofactor of NOS, thus avoiding uncoupled eNOS function and O2.overproduction [35].

\subsection{Vitamin $E$}

Vit $\mathrm{E}$ is a group of fat soluble molecules, known as one of the most potent antioxidants, among which $\alpha$-TOH stands out as one of the most active forms [74]. $\alpha-\mathrm{TOH}$ is the major peroxyl radical scavenger in biological lipid membranes [138, 139], because it acts like a lipid based free radical chain-breaking molecule, thereby inhibiting lipid peroxidation through its own conversion into an oxidized product, $\alpha$-tocopheroxyl radical [35]. To restore the $\alpha$-TOH, the $\alpha$-tocopheroxyl radical is reduced by redox-active molecules such as Vit $\mathrm{C}$ or ubiquinol [140]. If the $\alpha$-tocopheroxyl radical is not reduced, it can react with lipids and generates lipid radical compounds, producing damage to the lipid membranes. Therefore, to have a beneficial therapeutic effect, the $\alpha$-TOH requires coantioxidants such as Vit $\mathrm{C}[141]$.

The cardioprotective effect of Vit $\mathrm{E}$ has been described previously in a study, showing that higher $\alpha$-TOH baseline serum concentration is associated with a decreased risk overall and causes specific mortality for cardiovascular and heart diseases [142]. In IRI animal models, the $\alpha-$ TOH reduces infarct size and preserved cardiac function, in association with lower neutrophil infiltration locally in the ischemic myocardium and increases in anti-inflammatory monocyte function [143]. Furthermore, it has been reported positive effects in clinical studies of revascularization surgeries of the lower extremities [144], kidney transplantation [145], liver surgery [146], and aortic aneurysm repair [147]. In parallel, preoperative administration of Vit $\mathrm{E}$ has proven to exert beneficial effects on liver surgery by reducing the impact of IRI [148].

Besides its role as ROS scavenger, Vit E has been associated with increased GSH-Px activity [35] and decreased ROS production via down-regulation of NOX enzymes [136]. In addition, Vit $\mathrm{E}$ also has antiinflammatory effects by inhibiting the transcriptional activity of $\mathrm{NF}-\kappa \mathrm{B}$, that contributes to diminish the proinflammatory gene expression [149].

\subsection{N-Acetylcysteine}

$\mathrm{N}$-acetylcysteine (NAC) is an acetylated cysteine compound that acts as a blood antioxidant reserve. It could prevent the reduction of GSH/GSSG ratio during exposure to ascorbic acid by behaving as a GSH donor when it is oxidized to DHA [74]. 
In ischemia-reperfusion rat models it has been demonstrated that the administration of NAC by continuous infusion before, during and after reperfusion produced a smaller infarct size compared to the control group. However, this effect did not occur when NAC was administered as an intravenous bolus at the same dose [150]. Also, the results of a clinical trial showed a decrease in the incidence of postoperative atrial fibrillation in patients undergoing coronary artery bypass and valve surgery treated with intravenous infusion of NAC, before and after surgery [151].

Since co-administration of a GSH donor with Vit C shows a synergistic protective effect on infarct size in an isolated rat heart IRI model [152], it has been postulated that reinforcement antioxidant defenses with a GSH donor such as NAC could prevent the decrease in GSH and the reduction of the GSH/GSSG ratio during the administration of high doses of ascorbic acid to control burst of ROS in the reperfusion phase of AMI treatment $[135]$.

\subsection{Deferoxamine}

Deferoxamine (DFO) is a Food and Drug Administration (FDA) approved drug to treat either acute or chronic iron overload and it has a well-defined role as an iron chelator [153]. His effects in myocardial IRI are based on the increase in free iron during ischemic phase due media acidification, which promotes the mobilization of iron from intracellular ferritin. In the same way, once the reperfusion is onset, even if the iron levels decrease, the O2.contributes to more mobilization of iron from ferritin [135]. In fact, elevated serum FT levels is an important risk factor for developing AMI in middle-aged men without prior coronary artery disease [154]. Therefore, under conditions of oxidative stress, the LIP can react to produce $\cdot \mathrm{OH}$ in Fenton and Haber-Weiss reactions [74], as previously described.

The use of iron chelators at the onset of reperfusion has been proved to improve cardiac function relative to the control group [155]. Furthermore, when isolated and perfused rabbit cardiomyocytes are treated with DFO during ischemia and reperfusion, it has been associated with greater functional and metabolic recovery of the myocardium, as well as a reduction in the generation of ROS induced by perfusion, compared to the control group [156]. Likewise, in IRI canine model, pretreatment with DFO before ischemia, but not at the beginning of reperfusion, significantly reduced infarct size and GSSG release in the coronary sinus during reperfusion [157]. In addition, a clinical trial of patients with STEMI submitted to coronary angioplasty shows that intravenous bolus administration of $500 \mathrm{mg}$ of DFO immediately before surgery, followed by a 12-hour infusion to $50 \mathrm{mg} / \mathrm{kg}$, significantly reduced plasma levels of F2-isoprostane after angioplasty compared to control group [158].

DFO could have a synergistic role with ascorbate, since the latter reduces $\mathrm{Fe}^{3+}$ to $\mathrm{Fe}^{2+}$, which is the substrate of the Fenton reaction that leads to higher ROS production. Therefore, besides the iron overload during reperfusion, a high dose of intravenous Vit $\mathrm{C}$ infusion could interact with $\mathrm{Fe}^{2+}$, enhancing the pro-oxidant effects of Vit $\mathrm{C}$ [135]. In this scenario, the use of iron chelators such as DFO could be considered in conjunction with Vit C antioxidant therapy in patients with myocardial IRI.

In this regard, in an experimental sheep model it was shown that the combined use of ascorbic acid $(1.5 \mathrm{~g})$ and DFO $(1 \mathrm{~g})$ administered by intravenous infusion was protective against the development of ventricular arrhythmias induced by myocardial IRI, compared to the control group [159].

\subsection{Polyphenols}

This group of bioactive molecules currently occurring in some foods have antioxidant and anti-inflammatory effects. In addition, they also exhibit anti-cardiac hypertrophy, anti-atherosclerosis, anti-diabetic and anti-apoptotic effects through different signaling pathways [160].

According to the number of phenol rings and the elements that are attached to them, polyphenols can be classified into flavonoids and non-flavonoids. Flavonoids are present in plants, including vegetables and fruits, representing $2 / 3$ of the total polyphenols ingested in the diet. The best known flavonoids are quercetin, catechin, and myricetin [160]. In this regard, a myocardial IRI model study in rats described a cardioprotective role of quercetin by preventing a decrease in the $\mathrm{XDH}$ to $\mathrm{XO}$ ratio [161].

On the other hand, the non-flavonoids are found in different citrus fruits and berries, coffee, olive and sesame. The most important non-flavonoids are phenolic acids, like resveratrol [160]. They have shown antioxidant and anti-inflammatory effects by reducing inflammatory markers, such as IL-1 $\beta$, IL-8, monocyte chemoattractant protein (MCP-1), COX-2, and iNOS [162]. Particularly, resveratrol increases the expression and activity of eNOS due their capacity to enhance the serine 1177 residue phosphorylation, diminishing the endogenous eNOS inhibitor asymmetric dimethylarginine (ADMA) [163], and/or activating the AMP-activated protein kinase pathway in the cardiomyocyte [164].

Finally, the polyphenol treatment can stimulate the cytochrome $\mathrm{P} 450$ system, enhancing the functional recovery in a reperfused heart after ischemia, due the diminishes in the production of free radicals [165]. Also, the polyphenols administration has been shown to have antiarrhythmic effects and minimize mitochondrial IRI [166]. In addition, it can preserve the integrity of endothelial cells by stimulating the endothelium-derived hyperpolarizing factor $[167,168]$ and increase coronary flow via endothelium-dependent relaxation [169] and directly promote NO production.

\section{Novel Perspectives and Conclusions}

In the light of the results of the available studies up to date, myocardial IRI appears as a pathophysiological entity without therapeutic solution in the clinical practice. However, oxidative stress plays a leading role in the process of cell death and inflammation after reperfusion. Therefore, it has been postulated that reinforcing antioxidant defenses prior to reperfusion could improve the clinical outcomes, as assessed by markers of oxidative stress, infarct size, and myocardial function.

In this regard, the administration of Vit $\mathrm{C}$ at doses greater than $10 \mathrm{mml} / \mathrm{L}$ has proven to be safe, reducing markers of DNA damage and lipid peroxidation, as well as increasing the activity of the antioxidant enzyme SOD. Despite this, Vit $\mathrm{C}$ can act as a pro-oxidant species by reducing $\mathrm{Fe}^{3+}$ to $\mathrm{Fe}^{2+}$ and activating the Fenton reaction, 
leading to a greater amount of ROS production. Furthermore, during ischemia and reperfusion of the cardiomyocyte, there is a greater mobilization of $\mathrm{Fe}^{2+}$ from ferritin, which increases the LIP and ROS production.

For these reasons, a novel antioxidant therapy has been proposed as a cardioprotective treatment in patients with AMI subjected to reperfusion. It consists in a continuous intravenous infusion of high doses of Vit $\mathrm{C}$ combined with NAC and DFO, administered before and during reperfusion. This would allow to optimize the positive antioxidant effects that have been described with each drug separately in IRI models. On the one hand, NAC will act as a GSH donor, preventing the reduction of the GSH/GSSH ratio as a result of the oxidation of ascorbate to DHA. In turn, DFO will decrease $\mathrm{Fe}^{2+}$ levels as LIP, decreasing the ROS production rate due to the Fenton reaction. Thus, the co-administration of these drugs is expected to have a synergistic behavior in avoiding the deleterious effects of Vit $\mathrm{C}$.

To date, more studies of combination therapy are needed in subjects with AMI who underwent reperfusion via thrombolysis or percutaneous angioplasty, since the favorable results of experimental studies have not been able to be transferred to the clinical setting. However, the novel treatment described would allow a safe therapy with low doses of each drug, being a potential alternative in the short or medium term for the management of ROS burst during reperfusion in patients with AMI.

\section{Abbreviations:}

ACSL4, acyl-CoA synthetase long-chain family member 4; AIF, apoptosis-inducing factor; AMI, acute myocardial infarction; ATP, adenosine triphosphate; CAT, catalase; CHD, coronary heart disease; CVDs, cardiovascular diseases; DHA, dehydroascorbic acid; DUOX-x, dual oxidase-; eNOS, endothelial nitric oxide synthase; FT, ferritin; $\mathrm{Fe}^{2+}$, ferrous iron; $\mathrm{Fe}^{3+}$, ferric iron; GSH, reduced glutathione; GSH-Px, glutathione peroxidase; HIF-1, hypoxia-inducible factor $1 ; \mathrm{H}_{2} \mathrm{O}_{2}$ : hydrogen peroxide. IMI, ischemia-reperfusion injury; iNOS, inducible nitric oxide synthase; IPC, ischemic preconditioning; LDH, lactate dehydrogenase; LIP, labile iron pool; LRI, lethal reperfusion injury; $\mathrm{MCP}-1$, monocyte chemoattractant protein; MDA, malondialdehyde; mETC, mitochondrial electron transport chain; MPT, mitochondrial permeability transition pore; MVO, microvascular obstruction; NADPH, Nicotinamide Adenine Dinucleotide Phosphate; NF- $\kappa \beta$, nuclear factor kappa-light-chain-enhancer of activated B cells; nNOS, neuronal nitric oxide synthase; NO, nitric oxide; NOX, NADPH oxidases; ONOO-, peroxynitrite; $\mathrm{OH}$, hydroxyl radical; $\mathrm{O} 2-$, superoxide anion; ROS, reactive oxygen species; SERCA, sarcoendoplasmic reticulum $\mathrm{Ca}^{2+}$-ATPase; SOD, superoxide dismutase; STEMI, ST-segment elevation myocardial infarction; SR, sarcoplasmic reticulum; Vit E, vitamin E.; Vit C, vitamin C; XDH, xanthine dehydrogenase; XO, xanthine oxidase; $\alpha$-TOH, $\alpha$-tocopherol.

\section{References}

[1] World Health Organization, "Cardiovascular diseases (CVDs). Retrieved from: https://www.who.int/health[q] topics/cardiovascular-diseases\#tab=tab $1, " 2020$

[2] World Health Organization, "The top 10 causes of death. Retrieved from: https://www.who.int/news-room/factsheets/detail/the-top-10-causes-of-death," 2020.

[3] M. Ruiz-Meana and D. García-Dorado, "Pathophysiology of ischemia-reperfusion injury: New therapeutic options for acute myocardial infarction," Spanish Journal of Cardiology (English Edition), vol. 62, pp. 199-209, 2009.

[4] S. S. Virani, A. Alonso, H. Aparicio, E. Benjamin, M. Bittencourt, and C. Callaway, "American heart association council on epidemiology and prevention statistics committee and stroke statistics subcommittee. Heart Disease and Stroke Statistics-2021 Update: A Report from the American Heart Association," Circulation, vol. 143, pp. e254-e743, 2021.

[5] D. Garcia-Dorado, A. Rodríguez-Sinovas, M. Ruiz-Meana, and J. Inserte, "Protection against myocardial ischemia-reperfusion injury in clinical practice," Spanish Journal of Cardiology (English Edition), vol. 67, pp. 394-404, 2014.

[6] G. W. Reed, J. E. Rossi, and C. P. Cannon, "Acute myocardial infarction," The Lancet, vol. 389, pp. 197-2 $10,2017$.

[7] D. M. Yellon and D. J. Hausenloy, "Myocardial reperfusion injury," New England Journal of Medicine, vol. 357, pp. 1121-1135, 2007.

[8] D. J. Hausenloy and D. M. Yellon, "Myocardial ischemia-reperfusion injury: A neglected therapeutic target," The Journal of clinical investigation, vol. 123, pp. 92-100, 2013.Available at: https://doi.org/10.1172/jci62874.

[9] A. Mokhtari-Zaer, N. Marefati, S. L. Atkin, A. E. Butler, and A. Sahebkar, "The protective role of curcumin in myocardial ischemia-reperfusion injury," Journal of Cellular Physiology, vol. 234, pp. 214-222, 2018.

[10] S. Jolly, W. Kane, M. Bailie, G. Abrams, and B. Lucchesi, "Canine myocardial reperfusion injury. Its reduction by the combined administration of superoxide dismutase and catalase," Circulation Research, vol. 54, pp. 277-285, 1984.Available at: https://doi.org/10.1161/01.res.54.3.277.

[11] J. L. Zweier, J. T. Flaherty, and M. L. Weisfeldt, "Direct measurement of free radical generation following reperfusion of ischemic myocardium," Proceedings of the National Academy of Sciences, vol. 84, pp. 1404-1407, 1987.Available at: https://doi.org/10.1073/pnas.84.5.1404.

[12] J. L. Zweier, B. K. Rayburn, J. T. Flaherty, and M. L. Weisfeldt, "Recombinant superoxide dismutase reduces oxygen free radical concentrations in reperfused myocardium," The Journal of Clinical Investigation, vol. 80, pp. 1728-1734, 1987.Available at: https://doi.org/10.1172/jci113264.

[13] G. Ambrosio, M. L. Weisfeldt, W. E. Jacobus, and J. Flaherty, "Evidence for a reversible oxygen radical-mediated component of reperfusion injury: Reduction by recombinant human superoxide dismutase administered at the time of reflow," Circulation, vol. 75, pp. 282-291, 1987.Available at: https://doi.org/10.1161/01.cir.75.1.282.

[14] J. Zweier, "Measurement of superoxide-derived free radicals in the reperfused heart. Evidence for a free radical mechanism of reperfusion injury," Journal of Biological Chemistry, vol. 263, pp. 1353-1357, 1988.Available at: https://doi.org/10.1016/s00219258(19)57309-4.

[15] H. P. Grill, J. L. Zweier, P. Kuppusamy, M. L. Weisfeldt, and J. T. Flaherty, "Direct measurement of myocardial free radical generation in an in vivo model: Effects of postischemic reperfusion and treatment with human recombinant superoxide dismutase," Journal of the American College of Cardiology, vol. 20, pp. 1604-1611, 1992.Available at: https://doi.org/10.1016/0735$1097(92) 90457-\mathrm{x}$.

[16] S. Lecour, A. B. Baouali, V. Maupoil, R. Chahine, C. Abadie, A. Javouhey-Donzel, L. Rochette, and R. Nadeau, "Demonstration of the production of oxygen-centered free radicals during electrolysis using ESR spin-trapping techniques: effects on cardiac function in the isolated rat heart," Free Radical Biology and Medicine, vol. 24, pp. 573-579, 1998.Available at: https://doi.org/10.1016/s08915849(97)00294-3.

[17] F. Bernink, L. Timmers, A. Beek, M. Diamant, S. Roos, A. Van Rossum, and Y. Appelman, "Progression in attenuating myocardial reperfusion injury: An overview," International Journal of Cardiology, vol. 170, pp. 261-269, 2014.Available at: https://doi.org/10.1016/j.jjcard.2013.11.007.

[18] E. Braunwald and R. Kloner, "The stunned myocardium: Prolonged, postischemic ventricular dysfunction," Circulation, vol. 66, pp. 1146-1 149, 1982.Available at: https://doi.org/10.1161/01.cir.66.6.1146. 
[19] R. A. Kloner, R. Bolli, E. Marban, L. Reinlib, and E. Braunwald, "Medical and cellular implications of stunning, hibernation, and preconditioning: An NHLBI workshop," Circulation, vol. 97, pp. 1848-1867, 1998.Available at: preconditioning: An NHLBI wor
https://doi.org/10.1161/01.cir.97.18.1848.

[20] R. Bolli, "Mechanism of myocardial" stunning"," Circulation, vol. 82, pp. 723-738, 1990.Available at: https://doi.org/10.1161/01.cir.82.3.723.

[21] R. Bolli, Oxyradicals in the pathogenesis of myocardial stunning,". In: stunning, hibernation, and preconditioning: Clinical Pathophysiology of Myocardial Ischemia, (Heyndrickx GR, Vatner SF, Wijns W, eds). Philadelphia, Pa: Lippincott-Raven Press, 1997.

[22] H. Kusuoka and E. Marban, "Cellular mechanisms of myocardial stunning," Annual Review of Physiology, vol. 54, pp. 243-256, 1992.Available at: https://doi.org/10.1146/annurev.ph.54.030192.001331.

[23] E. Marban, Y. Koretsune, M. Corretti, V. Chacko, and H. Kusuoka, "Calcium and its role in myocardial cell injury during ischemia and reperfusion," Circulation, vol. 80, pp. IV 17-22, 1989.

[24] A. S. Manning and D. J. Hearse, "Reperfusion-induced arrhythmias: Mechanisms and prevention," Journal of Molecular and Cellular Cardiology, vol. 16, pp. 497-518, 1984.Available at: https://doi.org/10.1016/s0022-2828(84)80638-0.

[25] G. M. Fröhlich, P. Meier, S. K. White, D. M. Yellon, and D. J. Hausenloy, "Myocardial reperfusion injury: Looking beyond primary PCI," European Heart Journal, vol. 34, pp. 1714-1722, 2013.Available at: https://doi.org/10.1093/eurheartj/ehto90.

[26] R. C. Kukreja and Y. Janin, "Reperfusion injury: Basic concepts and protection strategies," Journal of Thrombosis and Thrombolysis, vol. 4, pp. 7-24, 1997.

[27] D. J. Hearse and T. Arpad, "Reperfusion-induced arrhythmias and free radicals: studies in the rat heart with DMPO," Journal of Cardiovascular Pharmacology, vol. 9, pp. 641-650, 1987.

[28] A. Krug, W. D. M. De Rochemont, and G. Korb, "Blood supply of the myocardium after temporary coronary occlusion," Circulation Research, vol. 19, pp. 57-62, 1966.Available at: https://doi.org/10.1161/01.res.19.1.57.

[29] R. A. Kloner, C. E. Ganote, and R. B. Jennings, "The "no-reflow" phenomenon after temporary coronary occlusion in the dog," The Journal of Clinical Investigation, vol. 54, pp. 1496-1508, 1974.Available at: https://doi.org/10.1172/jci 107898.

[30] R. Ferrari, C. Balla, M. Malagù, G. Guardigli, G. Morciano, M. Bertini, S. Biscaglia, and G. Campo, "Reperfusion damage-a story of success, failure, and hope-," Circulation Journal, vol. 81, pp. 131-141, 2017.

[31] H. Ito, "No-reflow phenomenon and prognosis in patients with acute myocardial infarction," Nature clinical practice Cardiovascular medicine, vol. 3, pp. 499-506, 2006.Available at: https://doi.org/10.1038/ncpcardio0632.

[32] A. K. Luo and K. C. Wu, "Imaging microvascular obstruction and its clinical significance following acute myocardial infarction," Heart Failure Reviews, vol. 11, pp. 305-312, 2006.Available at: https://doi.org/10.1007/s 10741-006-0231-0.

[33] G. Heusch, P. Kleinbongard, D. Böse, B. Levkau, M. Haude, R. Schulz, and R. Erbel, "Coronary microembolization: From bedside to bench and back to bedside," Circulation, vol. 120, pp. 1822-1836, 2009.Available at: https://doi.org/10.1161/circulationaha.109.888784.

[34] P. Kleinbongard, D. Böse, T. Baars, S. Möhlenkamp, T. Konorza, S. Schöner, M. Elter-Schulz, H. Eggebrecht, H. Degen, and M. Haude, "Vasoconstrictor potential of coronary aspirate from patients undergoing stenting of saphenous vein aortocoronary bypass grafts and its pharmacological attenuation," Circulation Research, vol. 108, pp. 344-352, 2011.Available at: https://doi.org/10.1161/circresaha.110.235713.

[35] R. Rodrigo, M. Libuy, F. Feliú, and D. Hasson, "Molecular basis of cardioprotective effect of antioxidant vitamins in myocardial infarction," BioMed Research International, vol. 2013, pp. 1-15, 2013.Available at: https://doi.org/10.1155/2013/437613.

[36] R. A. Kloner, "Does reperfusion injury exist in humans?," Journal of the American College of Cardiology, vol. 21, pp. 537-545, 1993.Available at: https://doi.org/10.1016/0735-1097(93)90700-b.

[37] M. H. Soonpaa and L. J. Field, "Survey of studies examining mammalian cardiomyocyte DNA synthesis," Circulation Research, vol. 83, pp. 15-26, 1998.Available at: https://doi.org/10.1161/01.res.83.1.15.

[38] S. Sanada, I. Komuro, and M. Kitakaze, "Pathophysiology of myocardial reperfusion injury: preconditioning, postconditioning, and translational aspects of protective measures," American Journal of Physiology-Heart and Circulatory Physiology, vol. 301, pp. H1723H1741, 2011.Available at: https://doi.org/10.1152/ajpheart.00553.2011.

[39] J. R. Neely and L. W. Grotyohann, "Role of glycolytic products in damage to ischemic myocardium. Dissociation of adenosine triphosphate levels and recovery of function of reperfused ischemic hearts," Circulation Research, vol. 55, pp. 816-824, 1984.Available at: https://doi.org/10.1161/01.res.55.6.816.

[40] M. M. Pike, C. S. Luo, M. D. Clark, K. A. Kirk, M. Kitakaze, M. C. Madden, E. J. Cragoe Jr, and G. M. Pohost, "NMR measurements of $\mathrm{Na}+$ and cellular energy in ischemic rat heart: Role of $\mathrm{Na}(+)-\mathrm{H}+$ exchange," American Journal of Physiology-Heart and Circulatory Physiology, vol. 265, pp. H2017-H2026, 1993.Available at: https://doi.org/10.1152/ajpheart.1993.265.6.h2017.

[41] M. Avkiran and M. S. Marber, "Na+/H+ exchange inhibitors for cardioprotective therapy: Progress, problems and prospects," Journal of the American College of Cardiology, vol. 39, pp. 747-753, 2002.Available at: https://doi.org/10.1016/s0735-1097(02)016935.

[42] R. Rodrigo, J. Gonzalez-Montero, and C. G. Sotomayor, "Novel combined antioxidant strategy against hypertension, acute myocardial infarction and postoperative atrial fibrillation," Biomedicines, vol. 9, pp. 620-640, 2021.

[43] H. Piper, D. Garcña-Dorado, and M. Ovize, "A fresh look at reperfusion injury," Cardiovascular Research, vol. 38, pp. 291-300, 1998.Available at: https://doi.org/10.1016/s0008-6363(98)00033-9.

[44] H. Piper, Y. Abdallah, and C. Schäfer, "The first minutes of reperfusion: A window of opportunity for cardioprotection," Cardiovascular Research, vol. 61, pp. 365-371, 2004.Available at: https://doi.org/10.1016/j.cardiores.2003.12.012.

[45] A. E. Rossi and R. T. Dirksen, "Sarcoplasmic reticulum: The dynamic calcium governor of muscle," Muscle \& Nerve: Official Journal of the American Association of Electrodiagnostic Medicine, vol. 33, pp. 715-731, 2006.Available at: https://doi.org/10.1002/mus.20512.

[46] M. I. Bak and J. S. Ingwall, "Contribution of $\mathrm{Na}+/ \mathrm{H}+$ exchange to $\mathrm{Na}+$ overload in the ischemic hypertrophied hyperthyroid rat heart," Cardiovascular Research, vol. 57, pp. 1004-1014, 2003.Available at: https://doi.org/10.1016/s0008-6363(02)00793-9.

[47] E. Murphy and C. Steenbergen, "Ion transport and energetics during cell death and protection," Physiology, vol. 23, pp. 115-123, 2008.Available at: https://doi.org/10.1152/physiol.00044.2007.

[48] D. Hearse, S. Humphrey, and E. Chain, "Abrupt reoxygenation of the anoxic potassium-arrested perfused rat heart: A study of myocardial enzyme release," Journal of Molecular and Cellular Cardiology, vol. 5, pp. 395-407, 1973.Available at: https://doi.org/10.1016/0022-2828(73)90030-8.

[49] N. S. Dhalla, A. B. Elmoselhi, T. Hata, and N. Makino, "Status of myocardial antioxidants in ischemia-reperfusion injury," Cardiovascular Research, vol. 47, pp. 446-456, 2000.

[50] S. Jeddi, S. Gheibi, K. Kashfi, M. Carlström, and A. Ghasemi, "Dose-dependent effects of long-term administration of hydrogen sulfide on myocardial ischemia-reperfusion injury in male wistar rats: Modulation of RKIP, NF- $\kappa$, and Oxidative Stress," International journal of molecular sciences, vol. 21 , pp. 1415-1434, 2020.Available at: https://doi.org/10.3390/ijms2 1041415.

[51] K. M. Venardos and D. M. Kaye, "Myocardial ischemia-reperfusion injury, antioxidant enzyme systems, and selenium: A review," Current Medicinal Chemistry, vol. 14, pp. 1539-1549, 2007.Available at: https://doi.org/10.2 174/092986707780831078.

[52] M. D. Brand, "The sites and topology of mitochondrial superoxide production," Experimental Gerontology, vol. 45, pp. 466-472, 2010.Available at: https://doi.org/10.1016/j.exger.2010.01.003.

[53] S. Cadenas, "ROS and redox signaling in myocardial ischemia-reperfusion injury and cardioprotection," Free Radical Biology and Medicine, vol. 117, pp. 76-89, 2018.Available at: https://doi.org/10.1016/j.freeradbiomed.2018.01.024.

[54] E. T. Chouchani, V. R. Pell, E. Gaude, D. Aksentijević, S. Y. Sundier, E. L. Robb, A. Logan, S. M. Nadtochiy, E. N. Ord, and A. C. Smith, "Ischaemic accumulation of succinate controls reperfusion injury through mitochondrial ROS," Nature, vol. 515, pp. 431435, 2014.Available at: https://doi.org/10.1038/nature13909.

[55] E. T. Chouchani, V. R. Pell, A. M. James, L. M. Work, K. Saeb-Parsy, C. Frezza, T. Krieg, and M. P. Murphy, "A unifying mechanism for mitochondrial superoxide production during ischemia-reperfusion injury," Cell Metabolism, vol. 23, pp. 254-263, 2016.Available at: https://doi.org/10.1016/j.cmet.2015.12.009. 
[56] D. N. Granger and P. R. Kvietys, "Reperfusion injury and reactive oxygen species: The evolution of a concept," Redox Biology, vol. 6, pp. 524-551, 2015.Available at: https://doi.org/10.1016/j.redox.2015.08.020.

[57] F. H. Epstein and J. M. McCord, "Oxygen-derived free radicals in postischemic tissue injury," New England Journal of Medicine, vol. 312, pp. 159-163, 1985.Available at: https://doi.org/10.1056/nejm198501173120305.

[58] K. A. Reimer and R. Jennings, "Failure of the xanthine oxidase inhibitor allopurinol to limit infarct size after ischemia and reperfusion in dogs," Circulation, vol. 71, pp. 1069-1075, 1985.Available at: https://doi.org/10.1161/01.cir.71.5.1069.

[59] M. S. Alkaitis and M. J. Crabtree, "Recoupling the cardiac nitric oxide synthases: Tetrahydrobiopterin synthesis and recycling," Current heart Failure Reports, vol. 9, pp. 200-210, 2012.Available at: https://doi.org/10.1007/s 11897-012-0097-5.

[60] M. E. Armitage, K. Wingler, H. H. Schmidt, and M. La, "Translating the oxidative stress hypothesis into the clinic: NOX versus NOS," Journal of Molecular Medicine, vol. 87, pp. 1071-1076, 2009.Available at: https://doi.org/10.1007/s00109-009-0544-2.

[61] J. Vásquez-Vivar, B. Kalyanaraman, P. Martásek, N. Hogg, B. S. S. Masters, H. Karoui, P. Tordo, and K. A. Pritchard, "Superoxide generation by endothelial nitric oxide synthase: The influence of cofactors," Proceedings of the National Academy of Sciences, vol. 95, pp. 9220-9225, 1998.Available at: https://doi.org/10.1073/pnas.95.16.9220.

[62] M. Neri, I. Riezzo, N. Pascale, C. Pomara, and E. Turillazzi, "Ischemia/reperfusion injury following acute myocardial infarction: A critical issue for clinicians and forensic pathologists," Mediators of Inflammation, pp. 1-14, 2017.Available at: https://doi.org/10.1155/2017/7018393.

[63] B. I. Jugdutt, "Nitric oxide and cardioprotection during ischemia-reperfusion," Heart Failure Reviews, vol. 7, pp. 391-405, 2002.

[64] C. Szabó, H. Ischiropoulos, and R. Radi, "Peroxynitrite: biochemistry, pathophysiology and development of therapeutics," Nature reviews Drug discovery, vol. 6, pp. 662-680, 2007.

[65] W. Yasmin, K. D. Strynadka, and R. Schulz, "Generation of peroxynitrite contributes to ischemia-reperfusion injury in isolated rat hearts," Cardiovascular Research, vol. 33, pp. 422-432, 1997.Available at: https://doi.org/10.1016/s0008-6363(96)00254-4.

[66] I. Takac, K. Schröder, L. Zhang, B. Lardy, N. Anilkumar, J. D. Lambeth, A. M. Shah, F. Morel, and R. P. Brandes, "The E-loop is involved in hydrogen peroxide formation by the NADPH oxidase Nox4," Journal of Biological Chemistry, vol. 286, pp. 13304-13313, 2011.

[67] S. Altenhöfer, P. W. Kleikers, K. A. Radermacher, P. Scheurer, J. R. Hermans, P. Schiffers, H. Ho, K. Wingler, and H. H. Schmidt, "The NOX toolbox: Validating the role of NADPH oxidases in physiology and disease," Cellular and Molecular Life Sciences, vol. 69, pp. 2327-2343, 2012.

[68] K. D. Martyn, L. M. Frederick, K. Von Loehneysen, M. C. Dinauer, and U. G. Knaus, "Functional analysis of Nox4 reveals unique characteristics compared to other NADPH oxidases," Cellular Signalling, vol. 18, pp. 69-82, 2006.Available at: https://doi.org/10.1007/978-1-4939-9424-3_26.

[69] T. Kahles and R. P. Brandes, "Which NADPH oxidase isoform is relevant for ischemic stroke? The case for nox 2," Antioxidants \& Redox Signaling, vol. 18, pp. 1400-1417, 2013.Available at: https://doi.org/10.1089/ars.2012.4721.

[70] K. Bedard and K.-H. Krause, "The NOX family of ROS-generating NADPH oxidases: Physiology and pathophysiology," Physiological Reviews, vol. 87, pp. 245-313, 2007.Available at: https://doi.org/10.1152/physrev.00044.2005.

[71] R. P. Brandes, N. Weissmann, and K. Schröder, "NADPH oxidases in cardiovascular disease," Free Radical Biology and Medicine, vol. 49, pp. 687-706, 2010.Available at: https://doi.org/10.1016/j.freeradbiomed.2010.04.030.

[72] N. E. Hahn, C. Meischl, T. Kawahara, R. J. Musters, V. M. Verhoef, J. van der Velden, A. B. Vonk, W. J. Paulus, A. C. van Rossum, and H. W. Niessen, "NOX5 expression is increased in intramyocardial blood vessels and cardiomyocytes after acute myocardial infarction in humans," The American Journal of Pathology, vol. 180, pp. 2222-2229, 2012.Available at: https://doi.org/10.1016/j.ajpath.2012.02.018.

[73] S. Matsushima, J. Kuroda, T. Ago, P. Zhai, Y. Ikeda, S. Oka, G.-H. Fong, R. Tian, and J. Sadoshima, "Broad suppression of NADPH oxidase activity exacerbates ischemia/reperfusion injury through inadvertent downregulation of hypoxia-inducible factor$1 \alpha$ and upregulation of peroxisome proliferator-activated receptor- $\alpha$," Circulation Research, vol. 112, pp. 1135-1149, 2013.Available at: https://doi.org/10.1161/circresaha.111.300171.

[74] J. Lillo-Moya, C. Rojas-Solé, D. Muñoz-Salamanca, E. Panieri, L. Saso, and R. Rodrigo, "Targeting ferroptosis against ischemia/reperfusion cardiac injury," Antioxidants, vol. 10, pp. 667-692, 2021.

[75] A. Paterek, U. Mackiewicz, and M. Mączewski, "Iron and the heart: A paradigm shift from systemic to cardiomyocyte abnormalities," Journal of Cellular Physiology, vol. 234, pp. 21613-21629, 2019.Available at: https://doi.org/10.1002/jcp.28820.

[76] F. Petrat, H. De Groot, R. Sustmann, and U. Rauen, "The chelatable iron pool in living cells: A methodically defined quantity," Biological Chemistry, vol. 383, pp. 489-502, 2002, 2002.

[77] T. Nakamura, I. Naguro, and H. Ichijo, "Iron homeostasis and iron-regulated ROS in cell death, senescence and human diseases," Biochimica et Biophysica Acta (BBA)-General Subjects, vol. 1863, pp. 1398-1409, 2019.Available at: https://doi.org/10.1016/j.bbagen.2019.06.010.

[78] J. P. Kehrer, "The Haber-Weiss reaction and mechanisms of toxicity," Toxicology, vol. 149, pp. 43-50, 2000.Available at: https://doi.org/10.1016/s0300-483x(00)00231-6.

[79] J. P. Friedmann Angeli, M. Schneider, B. Proneth, Y. Y. Tyurina, V. A. Tyurin, and V. J. Hammond, "Inactivation of the ferroptosis regulator GPX4 triggers acute renal failure in mice," Nature Cell Biology, vol. 16, pp. 1180-1191, 2014.Available at: https://doi.org/10.1038/ncb3064.

[80] H. Lee, F. Zandkarimi, Y. Zhang, J. K. Meena, J. Kim, L. Zhuang, S. Tyagi, L. Ma, T. F. Westbrook, and G. R. Steinberg, "Energystress-mediated AMPK activation inhibits ferroptosis," Nature Cell Biology, vol. 22, pp. 225-234, 2020.Available at: https://doi.org/10.1038/s41556-020-0461-8.

[81] L.-J. Tang, X.-J. Luo, H. Tu, H. Chen, X.-M. Xiong, N.-S. Li, and J. Peng, "Ferroptosis occurs in phase of reperfusion but not ischemia in rat heart following ischemia or ischemia/reperfusion," Naunyn-Schmiedeberg's Archives of Pharmacology, vol. 394, pp. 401-410, 202 1.Available at: https://doi.org/10.1007/s002 10-020-01932-z.

[82] Y. Li, D. Feng, Z. Wang, Y. Zhao, R. Sun, D. Tian, D. Liu, F. Zhang, S. Ning, and J. Yao, "Ischemia-induced ACSL4 activation contributes to ferroptosis-mediated tissue injury in intestinal ischemia/reperfusion," Cell Death छ Differentiation, vol. 26, pp. 22842299, 2019.Available at: https://doi.org/10.1038/s41418-019-0299-4.

[83] C. Schäfer, Y. Ladilov, J. Inserte, M. Schäfer, S. Haffner, D. Garcia-Dorado, and H. Piper, "Role of the reverse mode of the $\mathrm{Na}+\mathrm{Ca} 2+$ exchanger in reoxygenation-induced cardiomyocyte injury," Cardiovascular Research, vol. 51, pp. 241-250, 2001.Available at: https://doi.org/10.1016/s0008-6363(01)00282-6.

[84] M. Kitakaze, "How to mediate cardioprotection in ischemic hearts—accumulated evidence of basic research should translate to clinical medicine," Cardiovascular Drugs and Therapy, vol. 24, pp. 217-223, 2010.Available at: https://doi.org/10.1007/s 10557-0106248-6.

[85] Z.-Q. Zhao, "Oxidative stress-elicited myocardial apoptosis during reperfusion," Current Opinion in Pharmacology, vol. 4, pp. 159165, 2004.Available at: https://doi.org/10.1016/j.coph.2003.10.010.

[86] T. Kalogeris, Y. Bao, and R. J. Korthuis, "Mitochondrial reactive oxygen species: A double edged sword in ischemia/reperfusion vs preconditioning," Redox Biology, vol. 2, pp. 702-714, 2014.Available at: https://doi.org/10.1016/j.redox.2014.05.006.

[87] L. Li, Y. Zhou, Y. Li, L. Wang, L. Sun, L. Zhou, H. Arai, Y. Qi, and Y. Xu, "Aqueous extract of Cortex Dictamni protects H9c2 cardiomyocytes from hypoxia/reoxygenation-induced oxidative stress and apoptosis by PI3K/Akt signaling pathway," Biomedicine E Pharmacotherapy, vol. 89, pp. 233-244, 2017.Available at: https://doi.org/10.1016/j.biopha.2017.02.013.

[88] A. Haunstetter and S. Izumo, "Apoptosis: Basic mechanisms and implications for cardiovascular disease," Circulation Research, vol. 82, pp. 1111-1129, 1998.Available at: https://doi.org/10.1161/01.res.82.11.1111.

[89] E. Marban, Y. Koretsune, and H. Kusuoka, "Disruption of intracellular ca2+ homeostasis in hearts reperfused after prolonged episodes of ischemia," Annals of the New York Academy of Sciences, vol. 723, pp. 38-50, 1994.Available at: https://doi.org/10.1111/j.1749-6632.1994.tb36715.x. 
[90] W. R. Herzog, R. A. Vogel, M. L. Schlossberg, L. R. Edenbaum, H. J. Scott, and V. L. Serebruany, "Short-term low dose intracoronary diltiazem administered at the onset of reperfusion reduces myocardial infarct size," International Journal of Cardiology, vol. 59, pp. 21-27, 1997.Available at: https://doi.org/10.1016/s0167-5273(96)02883-5.

[91] M. Miyamae, S. A. Camacho, M. W. Weiner, and V. M. Figueredo, "Attenuation of postischemic reperfusion injury is related to prevention of $[\mathrm{Ca} 2+] \mathrm{m}$ overload in rat hearts," American Journal of Physiology-Heart and Circulatory Physiology, vol. 271, pp. H2 145-H2 153, 1996.Ávailable at: https://doi.org/10.1152/ajpheart.1996.271.5.h2145.

[92] F. W. Bär, D. Tzivoni, M. T. Dirksen, A. Fernández-Ortiz, G. R. Heyndrickx, J. Brachmann, J. H. Reiber, N. Avasthy, J. Tatsuno, and M. Davies, "Results of the first clinical study of adjunctive CAldaret (MCC-135) in patients undergoing primary percutaneous coronary intervention for ST-Elevation Myocardial Infarction: the randomized multicentre CASTEMI study," European Heart Journal, vol. 27, pp. 2516-2523, 2006.Available at: https://doi.org/10.1093/eurheartj/ehl304.

[93] J. Lemasters, J. Bond, E. Chacon, I. Harper, S. Kaplan, H. Ohata, D. Trollinger, B. Herman, and W. Cascio, "The pH paradox in ischemia-reperfusion injury to cardiac myocytes," Myocardial Ischemia: Mechanisms, Reperfusion, Protection, vol. 76, pp. 99-114, 1996.Available at: https://doi.org/10.1007/978-3-0348-8988-9_7.

[94] L. He and J. J. Lemasters, "Regulated and unregulated mitochondrial permeability transition pores: A new paradigm of pore structure and function?," FEBS Letters, vol. 512, pp. 1-7, 2002.Available at: https://doi.org/10.3410/f.1004351.49904.

[95] E. J. Griffiths and A. P. Halestrap, "Mitochondrial non-specific pores remain closed during cardiac ischaemia, but open upon reperfusion," Biochemical Journal, vol. 307, pp. 93-98, 1995.Available at: https://doi.org/10.1042/bj3070093.

[96] G. Morciano, C. Giorgi, M. Bonora, S. Punzetti, R. Pavasini, M. R. Wieckowski, G. Campo, and P. Pinton, "Molecular identity of the mitochondrial permeability transition pore and its role in ischemia-reperfusion injury," Journal of Molecular and Cellular Cardiology, vol. 78, pp. 142-153, 2015.Available at: https://doi.org/10.1016/j.yjmcc.2014.08.015.

[97] D. J. Hausenloy, H. L. Maddock, G. F. Baxter, and D. M. Yellon, "Inhibiting mitochondrial permeability transition pore opening: A new paradigm for myocardial preconditioning?," Cardiovascular Research, vol. 55, pp. 534-543, 2002.Available at: https://doi.org/10.1016/s0008-6363(02)00455-8.

[98] D. J. Hausenloy, M. R. Duchen, and D. M. Yellon, "Inhibiting mitochondrial permeability transition pore opening at reperfusion protects against ischaemia-reperfusion injury," Cardiovascular Research, vol. 60, pp. 617-625, 2003.Available at: https://doi.org/10.1016/j.cardiores.2003.09.025.

[99] L. Argaud, O. Gateau-Roesch, D. Muntean, L. Chalabreysse, J. Loufouat, D. Robert, and M. Ovize, "Specific inhibition of the mitochondrial permeability transition prevents lethal reperfusion injury," Journal of Molecular and Cellular Cardiology, vol. 38, pp. 367-374, 2005.

[100] A. Skyschally, R. Schulz, and G. Heusch, "Cyclosporine A at reperfusion reduces infarct size in pigs," Cardiovascular Drugs and Therapy, vol. 24, pp. 85-87, 2010.Available at: https://doi.org/10.1007/s10557-010-6219-y.

[101] U. Zeymer, H. Suryapranata, J. P. Monassier, G. Opolski, J. Davies, and G. Rasmanis, "Exchange inhibitor eniporide as an adjunct to early reperfusion therapy for acute myocardial infarction. results of the evaluation of the safety and cardioprotective effects of eniporide in acute myocardial infarction (ESCAMI) trial," Journal of the American College of Cardiology, vol. 38, pp. 1644-1650, 2001.

[102] J. Vinten-Johansen, "Involvement of neutrophils in the pathogenesis of lethal myocardial reperfusion injury," Cardiovascular Research, vol. 61, pp. 481-497, 2004.Available at: https://doi.org/10.1016/j.cardiores.2003.10.011.

[103] F. J. Pashkow, "Oxidative stress and inflammation in heart disease: Do antioxidants have a role in treatment and/or prevention?," International Journal of Inflammation, vol. 2011, pp. 1-9, 2011 .Available at: https://doi.org/10.4061/2011/514623.

[104] R. Gill, A. Tsung, and T. Billiar, "Linking oxidative stress to inflammation: Toll-like receptors," Free Radical Biology and Medicine, vol. 48, pp. 1121-1132, 2010.Available at: https://doi.org/10.1016/j.freeradbiomed.2010.01.006.

[105] F. Wang, H. Wang, X. Liu, H. Yu, X. Huang, W. Huang, and G. Wang, "Neuregulin-1 alleviate oxidative stress and mitigate inflammation by suppressing NOX4 and NLRP3/caspase-1 in myocardial ischaemia-reperfusion injury," Journal of Cellular and Molecular Medicine, vol. 25, pp. 1783-1795, 2021.

[106] Y. Liu, K. Lian, L. Zhang, R. Wang, F. Yi, C. Gao, C. Xin, D. Zhu, Y. Li, and W. Yan, "TXNIP mediates NLRP3 inflammasome activation in cardiac microvascular endothelial cells as a novel mechanism in myocardial ischemia/reperfusion injury," Basic Research in Cardiology, vol. 109, pp. 415-430, 2014.Available at: https://doi.org/10.1 136/heartjnl-2013-304613.178.

[107] A. J. Ludman, D. M. Yellon, and D. J. Hausenloy, "Cardiac preconditioning for ischaemia: Lost in translation," Disease Models \& Mechanisms, vol. 3, pp. 35-38, 2010.

[108] D. J. Hausenloy, G. Baxter, R. Bell, H. E. Bøtker, S. M. Davidson, J. Downey, G. Heusch, M. Kitakaze, S. Lecour, and R. Mentzer, "Translating novel strategies for cardioprotection: The Hatter Workshop Recommendations," Basic Research in Cardiology, vol. 105, pp. 677-686, 2010.

[109] D. J. Hausenloy, J. A. Barrabes, H. E. Bøtker, S. M. Davidson, F. Di Lisa, J. Downey, T. Engstrom, P. Ferdinandy, H. A. CarbreraFuentes, and G. Heusch, "Ischaemic conditioning and targeting reperfusion injury: A 30 year voyage of discovery," Basic Research in Cardiology, vol. 111, pp. 1-24, 2016.

[110] D. J. Hausenloy and D. M. Yellon, "Ischaemic conditioning and reperfusion injury," Nature Revierws Cardiology, vol. 13, pp. 193-209, 2016.Available at: https://doi.org/10.1038/nrcardio.2016.5.

[111] C. E. Murry, R. B. Jennings, and K. A. Reimer, "Preconditioning with ischemia: A delay of lethal cell injury in ischemic myocardium," Circulation, vol. 74, pp. 1124-1136, 1986.Available at: https://doi.org/10.1161/o1.cir.74.5.1124.

[112] Z. Cai, H. Zhong, M. Bosch-Marce, K. Fox-Talbot, L. Wang, C. Wei, M. A. Trush, and G. L. Semenza, "Complete loss of ischaemic preconditioning-induced cardioprotection in mice with partial deficiency of HIF-1 $\alpha$," Cardiovascular Rsearch, vol. 77, pp. 463-470, 2008.Available at: https://doi.org/10.1093/cvr/cvm035.

[113] S. A. Javadov, S. Clarke, M. Das, E. J. Griffiths, K. H. Lim, and A. P. Halestrap, "Ischaemic preconditioning inhibits opening of mitochondrial permeability transition pores in the reperfused rat heart," The Journal of Physiology, vol. 549, pp. 513-524, 2003.

[114] L. Argaud, O. Gateau-Roesch, L. Chalabreysse, L. Gomez, J. Loufouat, F. Thivolet-Béjui, D. Robert, and M. Ovize, "Preconditioning delays Ca2+-induced mitochondrial permeability transition," Cardiovascular research, vol. 61, pp. 115-122, 2004.

[115] D. J. Hausenloy, D. M. Yellon, S. Mani-Babu, and M. R. Duchen, "Preconditioning protects by inhibiting the mitochondrial permeability transition," American Journal of Physiology-Heart and Circulatory Physiology, vol. 287, pp. H841-H849, 2004.Available at: https://doi.org/10.1152/ajpheart.00678.2003.

[116] L. Argaud, O. Gateau-Roesch, O. Raisky, J. Loufouat, D. Robert, and M. Ovize, "Postconditioning inhibits mitochondrial permeability transition," Circulation, vol. 111, pp. 194-197, 2005.Available at: https://doi.org/10.1161/01.cir.0000151290.04952.3b.

[117] H. Frikke-Schmidt, P. Tveden-Nyborg, and J. Lykkesfeldt, Vitamin C in human nutrition," In: "Vitamins in the prevention of human disease", (Herrmann, W., Obeid, R., Eds.). Berlin, Germany: De Gruyter, 2011.

[118] M. Levine, S. J. Padayatty, and M. G. Espey, "Vitamin C: A concentration-function approach yields pharmacology and therapeutic discoveries," Advances in Nutrition, vol. 2, pp. 78-88, 2011.Available at: https://doi.org/10.3945/an.1 10.000109.

[119] C. I. Rivas, F. A. Zuniga, A. Salas-Burgos, L. Mardones, V. Ormazabal, and J. C. Vera, "Vitamin C transporters," Journal of Physiology and Biochemistry, vol. 64, pp. 357-376, 2008.

[120] H. Takanaga, B. Mackenzie, and M. A. Hediger, "Sodium-dependent ascorbic acid transporter family SLC23," Pflügers Archiv, vol. 447, pp. 677-682, 2004.Available at: https://doi.org/10.1007/s00424-003-1104-1.

[121] S. J. Padayatty, A. Katz, Y. Wang, P. Eck, O. Kwon, J.-H. Lee, S. Chen, C. Corpe, A. Dutta, and S. K. Dutta, "Vitamin C as an antioxidant: Evaluation of its role in disease prevention," Journal of the American College of Nutrition, vol. 22, pp. 18-35, 2003.Available at: https://doi.org/10.1080/07315724.2003.10719272.

[122] F. Gao, C.-L. Yao, E. Gao, Q.-Z. Mo, W.-L. Yan, R. McLaughlin, B. L. Lopez, T. A. Christopher, and X. L. Ma, "Enhancement of glutathione cardioprotection by ascorbic acid in myocardial reperfusion injury," Journal of Pharmacology and Experimental Therapeutics, vol. 301 , pp. 543-550, 2002.

[123] M. Krajčovičová-Kudláčková, M. Dušinská, M. Valachovičová, P. Blažíček, and V. Paukova, "Products of DNA, protein and lipid oxidative damage in relation to vitamin C plasma concentration," Physiol Res, vol. 55, pp. 227-31, 2006. 
[124] P. Bhakuni, M. Chandra, and M. Misra, "Effect of ascorbic acid supplementation on certain oxidative stress parameters in the post reperfusion patients of myocardial infarction," Molecular and Cellular Biochemistry, vol. 290, pp. 153-158, 2006.Available at: https://doi.org/10.1007/s11010-006-9182-y.

[125] S. A. Khan, S. Bhattacharjee, M. O. A. Ghani, R. Walden, and Q. M. Chen, "Vitamin C for cardiac protection during percutaneous coronary intervention: A systematic review of randomized controlled trials," Nutrients, vol. 12, p. 2199, 2020.Available at: https://doi.org/10.3390/nu12082199.

[126] C. Gasparetto, A. Malinverno, D. Culacciati, D. Gritt, P. Prosperini, G. Specchia, and G. Ricevuti, "Antioxidant vitamins reduce oxidative stress and ventricular remodeling in patients with acute myocardial infarction," International Journal of Immunopathology and Pharmacology, vol. 18, pp. 487-496, 2005.Available at: https://doi.org/10.1177/039463200501800308.

[127] N. Valls, J. G. Gormaz, R. Aguayo, J. González, R. Brito, D. Hasson, M. Libuy, C. Ramos, R. Carrasco, and J. C. Prieto, "Amelioration of persistent left ventricular function impairment through increased plasma ascorbate levels following myocardial infarction," Redox Report, vol. 21, pp. 75-83, 2016.Available at: https://doi.org/10.1179/1351000215y.0000000018.

[128] S. Basili, G. Tanzilli, E. Mangieri, V. Raparelli, S. Di Santo, P. Pignatelli, and F. Violi, "Intravenous ascorbic acid infusion improves myocardial perfusion grade during elective percutaneous coronary intervention: Relationship with oxidative stress markers," JACC: Cardiovascular Interventions, vol. 3, pp. 22 1-229, 2010.Available at: https://doi.org/10.1016/j.jcin.2009.10.025.

[129] P. Pignatelli, G. Tanzilli, R. Carnevale, S. Di Santo, L. Loffredo, A. Celestini, M. Proietti, P. Tovaglia, E. Mangieri, and S. Basili, "Ascorbic acid infusion blunts CD4OL upregulation in patients undergoing coronary stent," Cardiovascular Therapeutics, vol. 29, pp. 385-394, 2011.Available at: https://doi.org/10.1111/j.1755-5922.2010.00168.x.

[130] Z. J. Wang, W. K. Hu, Y. Y. Liu, D. M. Shi, W. J. Cheng, Y. H. Guo, Q. Yang, Y. X. Zhao, and Y. J. Zhou, "The effect of intravenous vitamin $\mathrm{C}$ infusion on periprocedural myocardial injury for patients undergoing elective percutaneous coronary intervention," Canadian Journal of Cardiology, vol. 30, pp. 96-101, 2014.Available at: https://doi.org/10.1016/j.cjca.2013.08.018.

[131] T. S. Jackson, A. Xu, J. A. Vita, and J. J. F. Keaney, "Ascorbate prevents the interaction of superoxide and nitric oxide only at very high physiological concentrations," Circulation Research, vol. 83, pp. 916-922, 1998.Available at: https://doi.org/10.1161/01.res.83.9.916

[132] C. Ramos, R. Brito, J. González-Montero, N. Valls, J. G. Gormaz, J. C. Prieto, R. Aguayo, Á. Puentes, V. Noriega, and G. Pereira, "Effects of a novel ascorbate-based protocol on infarct size and ventricle function in acute myocardial infarction patients undergoing percutaneous coronary angioplasty," Archives of Medical Science: AMS, vol. 3, p. 558, 2017.Available at: https://doi.org/10.5114/aoms.2016.59713.

[133] R. Rodrigo, J. C. Prieto, and R. Castillo, "Cardioprotection against ischaemia/reperfusion by vitamins C and E plus n- 3 fatty acids: molecular mechanisms and potential clinical applications," Clinical Science, vol. 124, pp. 1-15, 2013.Available at: https://doi.org/10.1042/cs20110663.

[134] R. Rodrigo, J. C. Prieto, R. Aguayo, C. Ramos, Á. Puentes, A. Gajardo, E. Panieri, C. Rojas-Solé, J. Lillo-Moya, and L. Saso, "Joint cardioprotective effect of vitamin $\mathrm{C}$ and other antioxidants against reperfusion injury in patients with acute myocardial infarction undergoing percutaneous coronary intervention," Molecules, vol. 26, p. 5702, 2021.

[135] P. Parra and R. Rodrigo, "Novel antioxidant therapy against myocardial ischemia- reperfusion injury during percutaneous coronary angioplasty," Free Radicals and Diseases, chapter 19, pp. 383-406, 2016.

[136] S. Ulker, P. P. McKeown, and U. Bayraktutan, "Vitamins reverse endothelial dysfunction through regulation of eNOS and NAD (P) H oxidase activities," Hypertension, vol. 41, pp. 534-539, 2003.Available at: https://doi.org/10.1161/01.hyp.0000057421.28533.37.

[137] J. M. Cárcamo, A. Pedraza, O. Bórquez-Ojeda, and D. W. Golde, "Vitamin C suppresses TNF $\alpha$-induced NFkB activation by

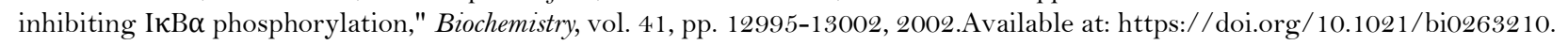

[138] J. M. Upston, P. K. Witting, A. J. Brown, R. Stocker, and J. F. Keaney Jr, "Effect of vitamin E on aortic lipid oxidation and intimal proliferation after arterial injury in cholesterol-fed rabbits," Free Radical Biology and Medicine, vol. 31, pp. 1245-1253, 2001.Available at: https://doi.org/10.1016/s0891-5849(01)00721-3.

[139] A. C. Terentis, S. R. Thomas, J. A. Burr, D. C. Liebler, and R. Stocker, "Vitamin E oxidation in human atherosclerotic lesions," Circulation Research, vol. 90, pp. 333-339, 2002.Available at: https://doi.org/10.1161/hh0302.104454.

[140] H. Shi, N. Noguchi, and E. Niki, "Comparative study on dynamics of antioxidative action of $\alpha$-tocopheryl hydroquinone, ubiquinol, and $\alpha$-tocopherol against lipid peroxidation," Free Radical Biology and Medicine, vol. 27, pp. 334-346, 1999.Available at: https://doi.org/10.1016/s0891-5849(99)00053-2.

[141] R. Brigelius-Flohé, F. J. Kelly, J. T. Salonen, J. Neuzil, J.-M. Zingg, and A. Azzi, "The European perspective on vitamin E: Current knowledge and future research," The American Journal of Clinical Nutrition, vol. 76, pp. 703-716, 2002.Available at: https://doi.org/10.1093/ajcn/76.4.703.

[142] J. Huang, S. J. Weinstein, K. Yu, S. Männistö, and D. Albanes, "Relationship between serum alpha-tocopherol and overall and cause-specific mortality: A 30-year prospective cohort analysis," Circulation Research, vol. 125, pp. 29-40, 2019.Available at: https://doi.org/10.1161/circresaha.1 19.314944

[143] M. Wallert, M. Ziegler, X. Wang, A. Maluenda, X. Xu, M. L. Yap, R. Witt, C. Giles, S. Kluge, and M. Hortmann, " $\alpha-$ Tocopherol preserves cardiac function by reducing oxidative stress and inflammation in ischemia/reperfusion injury," Redox Biology, vol. 26, p. 101292, 2019.Available at: https://doi.org/10.1016/j.redox.2019.101292.

[144] H. Rabl, G. Khoschsorur, and W. Petek, "Antioxidative vitamin treatment: Effect on lipid peroxidation and limb swelling after revascularization operations," World Journal of Surgery, vol. 19, pp. 738-744, 1995.Available at: https://doi.org/10.1007/bfo0295919.

[145] H. Rabl, G. Khoschsorur, T. Colombo, P. Petritsch, M. Rauchenwald, P. Költringer, F. Tatzber, and H. Esterbauer, "A multivitamin infusion prevents lipid peroxidation and improves transplantation performance," Kidney International, vol. 43, pp. 912917, 1993.Available at: https://doi.org/10.1038/ki.1993.128.

[146] H. Cerwenka, H. Bacher, G. Werkgartner, A. El-Shabrawi, F. Quehenberger, H. Hauser, and H. Mischinger, "Antioxidant treatment during liver resection for alleviation of ischemia-reperfusion injury," Hepato-gastroenterology, vol. 45, pp. 777-782, 1998.

[147] M. Wijnen, R. Roumen, H. Vader, and R. Goris, "A multiantioxidant supplementation reduces damage from ischaemia reperfusion in patients after lower torso ischaemia. A randomised trial," European Journal of Vascular and Endovascular Surgery, vol. 23, pp. 486490, 2002.Available at: https://doi.org/10.1053/ejvs.2002.1614.

[148] M. Bartels, H. K. Biesalski, K. Engelhart, G. Sendlhofer, P. Rehak, and E. Nagel, "Pilot study on the effect of parenteral vitamin E on ischemia and reperfusion induced liver injury: A double blind, randomized, placebo-controlled trial," Clinical Nutrition, vol. 23, pp. 1360-1370, 2004.Available at: https://doi.org/10.1016/j.clnu.2004.05.003.

[149] M. Kaileh and R. Sen, "Role of NF- $\mathrm{KB}$ in the anti-inflammatory effects of tocotrienols," Journal of the American College of Nutrition, vol. 29, pp. 334S-339S, 2010.Available at: https://doi.org/10.1080/07315724.2010.10719848.

[150] M. Abe, Y. Takiguchi, S. Ichimaru, K. Tsuchiya, and K. Wada, "Comparison of the protective effect of N-acetylcysteine by different treatments on rat myocardial ischemia-reperfusion injury," Journal of Pharmacological Sciences, vol. 106, pp. 571-577, 2008.Available at: https://doi.org/10.1254/jphs.fpoo71664.

[151] M. Ozaydin, O. Peker, D. Erdogan, S. Kapan, Y. Turker, E. Varol, F. Ozguner, A. Dogan, and E. Ibrisim, "N-acetylcysteine for the prevention of postoperative atrial fibrillation: A prospective, randomized, placebo-controlled pilot study," European Heart Journal, vol. 29, pp. 625-631, 2008.Available at: https://doi.org/10.1093/eurheartj/ehn 179 .

[152] S. D. Bellows, S. L. Hale, B. Z. Simkhovich, G. L. Kay, and R. A. Kloner, "Do antioxidant vitamins reduce infarct size following acute myocardial ischemia/reperfusion?," Cardiovascular Drugs and Therapy, vol. 9, pp. 117-123, 1995.Available at: https://doi.org/10.1007/bfoo877751.

[153] S. Pucheu, C. Coudray, N. Tresallet, A. Favier, and J. De Leiris, "Effect of iron overload in the isolated ischemic and reperfused rat heart," Cardiovascular Drugs and Therapy, vol. 7, pp. 701-711, 1993.Available at: https://doi.org/10.1007/bfo0877824.

[154] J. T. Salonen, K. Nyyssönen, H. Korpela, J. Tuomilehto, R. Seppänen, and R. Salonen, "High stored iron levels are associated with excess risk of myocardial infarction in eastern Finnish men," Circulation, vol. 86, pp. 803-811, 1992. 
[155] S. Korkmaz, E. Barnucz, S. Loganathan, S. Li, T. Radovits, and P. Hegedus, "Q50, an Iron chelating and zinc-complexing agent, improves cardiac function in rat models of Ischemia/reperfusion-induced myocardial injury," Circulation Journal, vol. 77, pp. 18171826, 2013.Available at: https://doi.org/10.1253/circj.cj-12-1162.

[156] R. E. Williams, J. L. Zweier, and J. T. Flaherty, "Treatment with deferoxamine during ischemia improves functional and metabolic recovery and reduces reperfusion-induced oxygen radical generation in rabbit hearts," Circulation, vol. 83, pp. 1006-1014, 1991.Available at: https://doi.org/10.1161/01.cir.83.3.1006.

[157] E. J. Lesnefsky, J. E. Repine, and L. D. Horwitz, "Deferoxamine pretreatment reduces canine infarct size and oxidative injury," Journal of Pharmacology and Experimental Therapeutics, vol. 253, pp. 1103-1109, 1990.

[158] W. Chan, A. J. Taylor, A. H. Ellims, L. Lefkovits, C. Wong, B. A. Kingwell, A. Natoli, K. D. Croft, T. Mori, and D. M. Kaye, "Effect of iron chelation on myocardial infarct size and oxidative stress in ST-elevation-myocardial infarction," Circulation: Cardiovascular Interventions, vol. 5, pp. 270-278, 2012.Available at: https://doi.org/10.1161/circinterventions.111.966226.

[159] C. Katsouras, A. Karahaliou, V. Koulouras, D. Nikas, D. Niokou, G. Papadopoulos, G. Nakos, D. Sideris, and L. Michalis, "Ventricular arrhythmias and antioxidative medication: Experimental study," Hellenic Journal of Cardiology, vol. 49, pp. 320-328, 2008

[160] M. Cebova and O. Pechanova, "Protective effects of polyphenols against Ischemia/reperfusion injury," Molecules, vol. 25, pp. 1-20, 2020.

[161] J. Sanhueza, J. Valdes, R. Campos, A. Garrido, and A. Valenzuela, "Changes in the xanthine dehydrogenase/xanthine oxidase ratio in the rat kidney subjected to ischemia-reperfusion stress: preventive effect of some flavonoids," Research Communications in Chemical Pathology and Pharmacology, vol. 78, pp. 211-218, 1992.

[162] J. Miranda, A. Lasa, L. Aguirre, A. Fernandez-Quintela, I. Milton, and M. Portillo, "Potential application of non-flavonoid phenolics in diabetes: Antiinflammatory effects," Current Medicinal Chemistry, vol. 22, pp. 112-131, 2015.Available at: https://doi.org/10.2174/0929867321666140815123507.

[163] E. Andriambeloson, A. L. Kleschyov, B. Muller, A. Beretz, J. C. Stoclet, and R. Andriantsitohaina, "Nitric oxide production and endothelium-dependent vasorelaxation induced by wine polyphenols in rat aorta," British Journal of Pharmacology, vol. 120, pp. 1053-1058, 1997.Available at: https://doi.org/10.1038/sj.bjp.0701011.

[164] G. Du, L. Sun, R. Zhao, L. Du, J. Song, L. Zhang, and J. Zhang, "Polyphenols: Potential source of drugs for the treatment of ischaemic heart disease," Pharmacology \& Therapeutics, vol. 162, pp. 23-34, 2016.Available at: https://doi.org/10.1016/j.pharmthera.2016.04.008.

[165] X.-H. Ning, X. Ding, K. F. Childs, S. F. Bolling, and K. P. Gallagher, "Flavone improves functional recovery after ischemia in isolated reperfused rabbit hearts," The Journal of Thoracic and Cardiovascular Surgery, vol. 105, pp. 541-549, 1993.Available at: https://doi.org/10.1016/s0022-5223(19)34238-2.

[166] H. Van Jaarsveld, J. Kuyl, D. Schulenburg, and N. Wiid, "Effect of flavonoids on the outcome of myocardial mitochondrial ischemia/reperfusion injury," Research Communications in Molecular Pathology and Pharmacology, vol. 91, pp. 65-75, 1996.

[167] V. B. Schini-Kerth, C. Auger, J.-H. Kim, N. Étienne-Selloum, and T. Chataigneau, "Nutritional improvement of the endothelial control of vascular tone by polyphenols: Role of NO and EDHF," Pflügers Archiv-European Journal of Physiology, vol. 459, pp. 853862, 2010.Available at: https://doi.org/10.1007/s00424-010-0806-4.

[168] R. Andriantsitohaina, C. Auger, T. Chataigneau, N. Étienne-Selloum, H. Li, M. C. Martínez, and I. Laher, "Molecular mechanisms of the cardiovascular protective effects of polyphenols," British Journal of Nutrition, vol. 108, pp. 1532-1549, 2012.Available at: https://doi.org/10.1017/s0007114512003406.

[169] D. F. Fitzpatrick, S. L. Hirschfield, and R. G. Coffey, "Endothelium-dependent vasorelaxing activity of wine and other grape products," American Journal of Physiology-Heart and Circulatory Physiology, vol. 265, pp. H774-H778, 1993.Available at: https://doi.org/10.1152/ajpheart.1993.265.2.h774. 